\title{
Desempenho do revestimento de argamassas reforçadas com telas: estudo de fissuração e do comportamento mecânico
}

\author{
Performance of reinforced mortar with meshes: study of \\ cracking and mechanical behaviour
}

\section{Daniela Santana Musse \\ Vinícius Almeida Coelho \\ Jardel Pereira Gonçalves \\ Francisco Gabriel Santos Silva}

\section{Resumo}

A

utilização das telas para reforço da camada de revestimento em fachadas tem se tornado uma excelente aliada na prevenção e redução de fissuras, pois podem absorver as tensões que surgem no sistema de revestimento. Esta pesquisa busca avaliar a incidência de fissuras de revestimentos reforçados com telas, submetidos à variação térmica, visando contribuir para o conhecimento do desempenho e comportamento das telas nos revestimentos argamassados. Para tanto, foi avaliada a resistência à tração direta de três telas (uma de polietileno e duas galvanizadas) a serem empregadas como reforço em argamassas analisadas quanto à resistência à compressão, tração, flexão e cisalhamento. Em seguida, foram construídos protótipos de fachadas revestidos com reboco reforçado com tela observando-se o comportamento do sistema após carregamento térmico $\left(38^{\circ} \mathrm{C}\right.$ e $\left.80^{\circ} \mathrm{C}\right)$ por meio de termografia, mapeamento de fissuras e resistência ao impacto, avaliando-se, ainda, a eficiência de duas metodologias de reparo de fissuração (tela poliéster com massa acrílica e resina epóxi). Os resultados revelaram que a tela galvanizada eletrossoldada apresentou melhor desempenho ao absorver parte das tensões e reduzir as aberturas das fissuras, garantindo ao conjunto melhor resistência à flexão, e ambas as metodologias de reparo analisadas apresentaram desempenho adequado ante a exposição térmica.

Palavras-chave: Revestimento. Argamassa reforçada. Telas.

'Daniela Santana Musse ${ }^{1}$ Universidade Federal da Bahia Salvador - BA - Brasil

${ }^{2}$ Vinícius Almeida Coelho ${ }^{2}$ Universidade Federal da Bahia Salvador - BA - Brasil

${ }^{3}$ Jardel Pereira Gonçalves ${ }^{3}$ Universidade Federal da Bahia Salvador - BA - Brasil

${ }^{4}$ Francisco Gabriel Santos Silva ${ }^{4}$ Universidade Federal da Bahia Salvador - BA - Brasil

Recebido em 02/10/19 Aceito em 21/04/20

\section{Abstract}

The use of mesh for facade cladding reinforcement has become

ahighlyeffectiveway to help in preventing and reducing cracks, as it can absorb the stresses that occur in the coating system. This research study seeks to evaluate the incidence of cracks inmesh reinforced coatings submitted to thermal variation, aiming to contribute to the knowledge of the performance and behaviour of mesh in mortar coatings. Hence, the direct tensile strength of three differentmeshes (one made of polyethylene and two galvanised ones) was evaluated with regards to theiruse as reinforcement in mortars. The properties analysed were compression, tensile, flexion and shear strength. Thereafter, prototypes of facades coated with mortar reinforced with mesh were constructed, observing the behaviour of the system after thermal loading $\left(38^{\circ} \mathrm{C}\right.$ and $\left.80^{\circ} \mathrm{C}\right)$ by means of thermography, crack mapping and impact resistance, further evaluating the efficiency of two crack repair methodologies (polyester mesh with acrylic plaster and epoxy resin). The results revealed that the electro-welded galvanised mesh produced a better performance, as it absorbed part of the stresses and reduced the crack openings, guaranteeing better flexural strength. Bothrepair methodologies showed an adequate performance with regards to thermal exposure.

Keywords: Coating. Reinforced mortar. Mesh. 


\section{Introdução}

As camadas do sistema de revestimento apresentam deformações diferenciadas quando sujeitos a variações de temperatura devido aos diferentes valores de coeficiente de dilatação e módulo de deformação de seus constituintes, estando sujeitasa tensões de tração, compressão e cisalhamento em situações usuais de exposição (FIORITO, 1994).

Sob tais situações, quando há incompatibilidade entre as condições de deformação da base e a capacidade de acomodar as deformações da argamassa, pode ocorrer a fissuração do revestimento e, em casos mais graves, até seu desplacamento (ANTUNES; MASUERO; MAÇANEIRO, 2014; FIORITO, 1994).

Problemas dessa natureza, associados ao aparecimento de outras manifestações patológicas, devem-se tanto às solicitações provocadas pelas solicitações externas do ambiente de exposição quanto à falta de controle de qualidade dos materiais, carência de projeto e acompanhamento durante a execução da construção e ausência de normas técnicas específicas (OLIVEIRA et al., 2017), além de falhas de execução, tais como a produção de reboco com espessura superior àquela recomendada pela NBR 13749 (ABNT, 2013a) sem inserção de telas de ancoragem entre as camadas.

Quando propostas, as telas têm por objetivo absorver as tensões originadas principalmente na junção de materiais distintos, proporcionando ancoragem entre as camadas e contribuindo para a redução de desplacamentos. Seu uso, no entanto, ainda carece de padronização quanto às técnicas de execução e de estudos que analisem tanto o tipo de material empregado quanto o desempenho mecânico do sistema quando exposto a variações térmicas, solicitação a que os revestimentos externos são constantemente submetidos.

Nesse contexto, o presente estudo tem como propósito contribuir para o desenvolvimento de técnicas para sistemas de revestimento ao avaliar o desempenho de diferentes sistemas de revestimento reforçados com tela quando submetidos a variação de temperatura no que diz respeito à fissuração e ao desempenho mecânico sob impacto de corpo rígido, verificando, ainda, as propriedades mecânicas de resistência à compressão, tração, flexão e cisalhamento das argamassas utilizadas como revestimento, e a eficiência de duas metodologias de reparo das fissuras quando expostas novamente ao carregamento térmico.

\section{Referencial teórico}

As tensões que atuam deformando os revestimentos podem ser originadas por variações térmicas, retração da argamassa que liga os elementos das alvenarias, retração da argamassa utilizada no emboço ou no contrapiso e deformação diferencial devido aos variados valores de coeficiente de dilatação térmica linear e módulo de deformação dos materiais (FIORITO, 1994). Diversas características resistentes das alvenarias são diretamente dependentes do tipo de argamassa empregada (MOHAMAD; LOURENÇO; ROMAN, 2007).

O emprego de telas em matrizes cimentícias é conhecido por apresentar baixo custo, ser de fácil execução e compatível com diferentes cenários de aplicação (superfícies molhadas ou baixas temperaturas), produzindo bons resultados no controle de fissuração de elementos de concreto (KOUTAS et al., 2018) e no aumento da resistência mecânica de painéis de alvenaria (OLIVEIRA et al., 2017, 2018; AZEVEDO et al., 2019).

Seu uso também tem sido recomendado como reforço para as camadas de reboco em elementos expostos a cargas sísmicas (FAUZAN et al., 2018), visto que possibilita melhor distribuição das tensões e redução da fissuração decorrente das deformações (SHERMI; DUBEY, 2018), como material para construção de painéis para pequenas residências (MUGHAL; SALEM; ABBAS, 2019), e estudado como alternativa na execução de reforços estruturais (PADALU; SINGH; DAS, 2020), atuando de forma semelhante às técnicas de confinamento de materiais cimentícios (EWING; KOWALSKY, 2004; BARBOSA; LOURENÇO; HANAI, 2010).

A NBR 13749 (ABNT, 2013a) indica a utilização de telas no revestimento externo sempre que a argamassa ultrapassar 30 mm de espessura. Já a NBR 7200 (ABNT, 1998) orienta seu uso na junção de base composta de diferentes materiais se esta for submetida a esforços que gerem deformações diferenciais, como em balanços, platibandas e últimos pavimentos.

Apesar da larga utilização da argamassa reforçada, seu uso nas construções ainda carece de estudos que avaliem sua funcionalidade e durabilidade dentro do sistema de revestimento. A aplicação desse método exige conhecimento sobre o comportamento mecânico do material a ser utilizado como reforço, tal como sua durabilidade e comportamento em condição de variação de temperatura.

468 Musse, D. S.; Coelho, V. A.; Gonçalves, J. P.; Silva, F. G. S. 
Atualmente, existem poucas pesquisas que abordam o uso de telas para reforço em fachadas. Os que se destacam são os estudos de Gomes, Neves e Souza (2007) e Antunes e Masuero (2016). O trabalho de Gomes et al. (2007) avaliou vários tipos de telas em argamassa armada em duas posições no corpo de prova (na superfície e dentro da camada), estudando o comportamento de tração por compressão diametral e tração na flexão. Segundo estes autores, o uso de telas no sistema de revestimento é mais eficiente quando a tela é instalada próxima à superfície externa.

Antunes e Masuero (2016) desenvolveram um estudo de tração na flexão em quatropontos utilizando cinco diferentes tipos de tela de quatro fabricantes distintos. $O$ estudo foi com telas de dimensões $15 \times 30 \mathrm{~cm}$ inseridas a um terço da espessura da camada de $5 \mathrm{~cm}$ de argamassa industrializada. As autoras concluíram que as telas de malhas quadradas galvanizadas eletrossoldadas de fio de 1,24 mm, quando posicionadas na zona tracionada do emboço, apresentaram os melhores resultados de desempenho. Já as telas entrelaçadas de viveiro e pinteiro promoveram diminuição da resistência em relação à argamassa de referência devido ao efeito cisalhante que a tela promove no conjunto, além da incompatibilidade geométrica das malhas com as características reológicas da argamassa industrializada utilizada.

\section{Método \\ Materiais}

Neste estudo foram utilizadas duas espessuras de revestimento, sendo um revestimento de argamassa mista de $2,5 \mathrm{~cm}$ de espessura, e outro revestimento de $5 \mathrm{~cm}$ de espessura contendo uma camada de argamassa industrializada e outra de argamassa mista, com o intuito de aumentar a incidência de fissuração na argamassa entre as camadas.

Para a análise do reforço de cada tipo de tela no revestimento, foi necessáriaa utilização de uma argamassa mista com elevada incidência de fissuras, de traço 1:2,5:12:3,10 (cimento, cal, areia e água, em massa) e 1: 4,55: 8,05: 3,10 (cimento, cal, areia e água em volume).

Na produção da argamassa mista foi utilizado o cimento Portland CP II Z-32 (RS), cal hidratada CHI e areia com massa específica de $2,64 \mathrm{~kg} / \mathrm{dm}^{3}$, módulo de finura igual a 1,68 e dimensão máxima característica de $1,18 \mathrm{~mm}$. Já a argamassa industrializada corresponde a uma argamassa para reboco pronto extraforte, apropriada para aplicação em ambientes externos. De acordo com o fabricante, esse produto possui emsua composição química cimento Portland CP-32, dióxido de silício,silicato de alumínio, cálcio e ferro,materiais carbonáticos e impermeabilizantes. As características dessa argamassa, de acordo com a NBR 13281:2005, são:

(a) resistência à compressão: Classe P4 (4,0 a 6,5 MPa);

(b) densidade no estado endurecido: Classe M5 (1.600 a $2.000 \mathrm{~kg} / \mathrm{m}^{3}$ );

(c) resistência à tração na flexão: Classe R4 (2,0 a 3,5 MPa);

(d) coeficiente de capilaridade: Classe C3 (2,0 a 4,0 g/dm². $\left.\mathrm{min}^{1 / 2}\right)$;

(e) densidade de massa no estado a fresco: Classe D3 (1.400 a $\left.1.800 \mathrm{~kg} / \mathrm{m}^{3}\right)$;

(f) retenção de água: Classe U3 (80 a 90\%); e

(g) resistência potencial de aderência à tração: Classe $\mathrm{A} 3(\geq 0,3 \mathrm{MPa})$.

As diferentes características das argamassas utilizadas como revestimentos nos substratos de alvenaria estrutural foram estudadas conforme as recomendações da NBR 13281 (ABNT, 2005a) e apresentadas na Tabela 1.

A aderência à tração certifica a capacidade da argamassa de se manter aderida ao substrato, resistindo aos esforços de tração solicitados. A norma NBR 15258 (ABNT, 2005b) descreve o método de ensaio da resistência de aderência à tração para revestimentos de paredes e tetos, utilizando um equipamento de tração com aplicação lenta e progressiva da carga. Nota-se que a argamassa mista possui menor resistência de aderência à tração e maior porosidade em relação à argamassa industrializada, devido à maior quantidade de partículas finas emsua composição. O alto valor de absorção de água por capilaridade na argamassa mista prejudica suas propriedades mecânicas e permite o surgimento de fissuras, afetando a durabilidade do revestimento, o que permitiu o desenvolvimento do presente estudo. 
Tabela 1 - Caracterização das argamassas conforme a NBR 13281 (ABNT, 2005)

\begin{tabular}{l|l|c|c}
\hline \multicolumn{1}{c|}{ Norma } & \multicolumn{1}{c|}{ Determinação } & $\begin{array}{c}\text { Argamassa } \\
\text { industrializada }\end{array}$ & Argamassa mista \\
\hline $\begin{array}{l}\text { NBR } \\
\begin{array}{l}13276(A B N T, \\
2005 c)\end{array}\end{array}$ & Índice de consistência & $259 \mathrm{~mm}$ & $260 \mathrm{~mm}$ \\
\hline $\begin{array}{l}\text { NBR 13277 } \\
(\text { ABNT, 2005d) }\end{array}$ & Índice de retenção de água & $82 \%$ & $81 \%$ \\
\hline $\begin{array}{l}\text { NBR 13278 } \\
(\text { ABNT, 2005e) }\end{array}$ & Densidade de massa no estado fresco & $1.524 \mathrm{~kg} / \mathrm{m}^{3}$ & $2.047 \mathrm{~kg} / \mathrm{m}^{3}$ \\
\hline $\begin{array}{l}\text { NBR13279 } \\
(\mathrm{ABNT}, 2005 \mathrm{f})\end{array}$ & Resistência à tração na flexão & $2,3 \mathrm{MPa}$ & $0,8 \mathrm{MPa}$ \\
\hline $\begin{array}{l}\text { NBR 13279 } \\
(\mathrm{ABNT}, 2005 \mathrm{f})\end{array}$ & Resistência à compressão & $5,4 \mathrm{MPa}$ & $1,3 \mathrm{MPa}$ \\
\hline $\begin{array}{l}\text { NBR 13280 } \\
(\mathrm{ABNT}, 2005 \mathrm{~g})\end{array}$ & Densidade no estado endurecido & $1.711 \mathrm{~kg} / \mathrm{m}^{3}$ & $1.816 \mathrm{~kg} / \mathrm{m}^{3}$ \\
\hline $\begin{array}{l}\text { NBR 15259 } \\
(\mathrm{ABNT}, 2005 \mathrm{~h})\end{array}$ & Absorção de água por capilaridade & $7,5 \mathrm{~g} / \mathrm{dm}^{2} \cdot \mathrm{min}^{1 / 2}$ & $27,2 \mathrm{~g} / \mathrm{dm}{ }^{2} \cdot \mathrm{min}^{1 / 2}$ \\
\hline $\begin{array}{l}\text { NBR 15258 } \\
(\mathrm{ABNT}, 2005 \mathrm{~b})\end{array}$ & Resistência potencial de aderência à tração & $0,31 \mathrm{MPa}$ & $0,14 \mathrm{MPa}$ \\
\hline
\end{tabular}

Adotando os procedimentos da NBR 6136 (ABNT, 2014), os blocos de alvenaria estrutural com dimensões de 140x190x390 mm (L x A x C) utilizados na construção dos painéis possuem resistência à compressão pelo método da resistência característica da amostra (fbk) de 5,4 MPa. Já a absorção total encontrada foi de $5,70 \%$, enquadrando-se nos valores de referência estabelecidos pela referida norma. Por fim, utilizando o ensaio do índice de absorção inicial de água preconizado pela NBR 15270-3 (ABNT, 2005i) para blocos cerâmicos, notou-se que os blocos de concreto atingiram o critério estabelecido pela norma com $\left(28,09 \mathrm{~g} / 193,55 \mathrm{~cm}^{2}\right) / \mathrm{min}$, podendo ser assentados sem ser umedecidos.

O reforço das argamassas deu-se por meio da utilização de três diferentes tipos de telas disponíveis comercialmente, que são:

(a) tela 1: eletrossoldada galvanizada de malha quadrada de $25 \times 25 \mathrm{~mm}$ e fio de 1,24 mm, Figura 1a;

(b) tela 2: polietileno de malha hexagonal de $13 \mathrm{~mm}$ de malha e fio de 1,2 $\mathrm{mm}$, Figura 1b; e

(c) tela 3: galvanizada de malha hexagonal de $12,7 \mathrm{~mm}$ de malha e fio de $0,56 \mathrm{~mm}$, não eletrossoldada, Figura 1c.

Para serem utilizadas no estudo, essas telas foram ensaiadas de acordo com as técnicas de ensaio de tração adotadas por Antunes e Masuero (2013) e Pozzobon et al. (2014). Dessa forma, o ensaio foi realizado utilizando-se uma prensa da marca Emic com capacidade de carga de $20 \mathrm{KN}$ por meio de um aparato construído de acordo com o dispositivo criado por Pozzobon et al.(2014), com o objetivo de distribuir uniformemente a tensão de tração. O ensaio de tração é apresentado na Figura 2.

Para tanto, foram utilizadas seis amostras com dimensões úteis de 29,5x10 cm (Lx A), com velocidade de carregamento de $10 \mathrm{~mm} / \mathrm{min}$. A avaliação da capacidade de ruptura foi encontrada pela razão da carga máxima pela área estimada da tela (área da seção de cada fio multiplicada pelo número de fios longitudinais da amostra). A resistência à tração das telas é apresentada na Tabela 2.

Portanto, com base nos resultados encontrados de resistência à tração das telas, a tela 1, como esperado, apresentou maior capacidade de absorver as tensões, com baixa deformabilidade e maior rigidez, e a tela 2, maior deformação. Essesfatossãoclaramente explicados pela natureza de fabricação de cada tela, ou seja, a tela 1 é um produto formado por fios eletrossoldados que lhe garantem maior rigidez e menor deformação, ao contrário da tela 2, que é constituída por fios de material polimérico de elevada deformação, enquanto a tela 3 possui fios entrelaçados de menor espessura, fornecendo menor resistência quando comparada com a tela 1 (SCHIMELFENIG et al., 2018). 
Figura 1 - Telas de reforço utilizadas

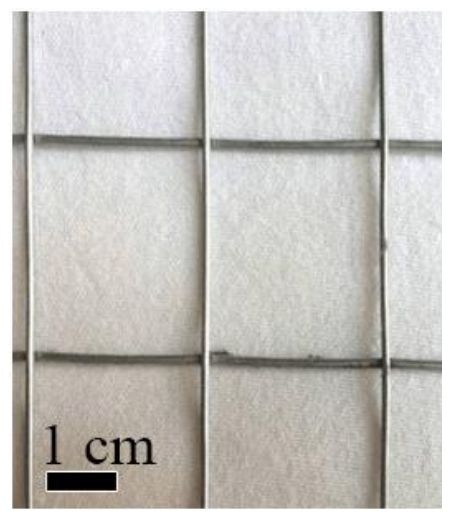

(a)

Figura 2 - Ensaio de tração das telas 1 (a), 2 (b) e 3 (c)

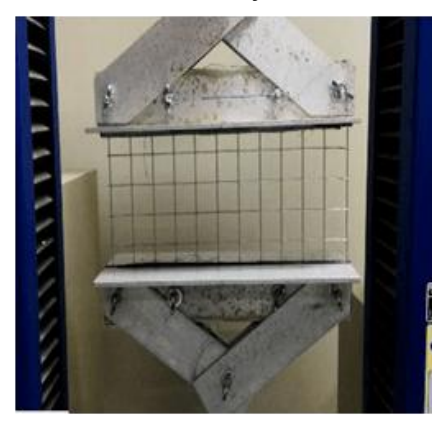

(a)

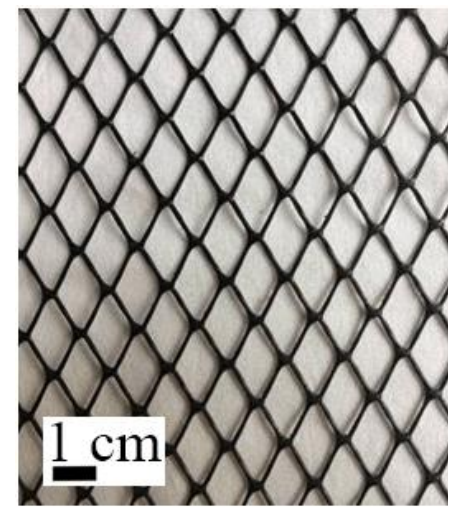

(b)



(b)

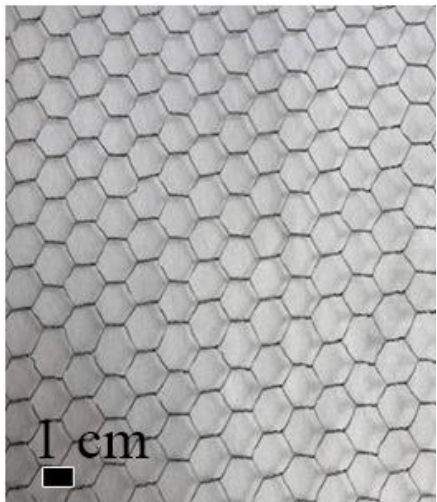

(c)

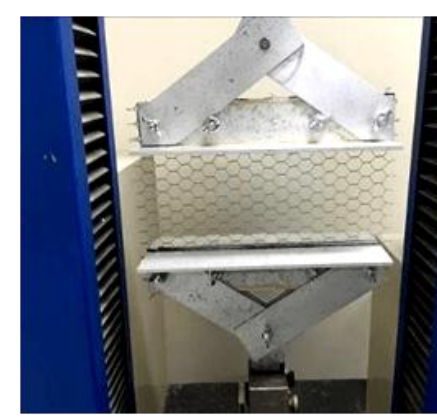

(c)

Tabela 2 - Resultados do ensaio de tração das telas

\begin{tabular}{c|c|c|c}
\hline Tipo de tela & Amostra & Carga máxima (N) & Limite de resistência (MPa) \\
\hline \multirow{3}{*}{ Tela 1(12 fios) } & Média & $5.880,08$ & 405,76 \\
& Desv. pad. & 301,10 & 20,78 \\
& CV\% & 5,12 & 5,12 \\
\hline \multirow{3}{*}{ Tela 2(20 fios) } & Média & 276,50 & 10,63 \\
& Desv. pad. & 31,57 & 1,21 \\
& CV\% & 11,42 & 11,42 \\
\hline \multirow{3}{*}{ Tela 3(21 fios) } & Média & 845,27 & 163,42 \\
& Desv. pad. & 24,72 & 4,78 \\
& CV\% & 2,92 & 2,92 \\
\hline
\end{tabular}

\section{Avaliação mecânica das argamassas armadas em corpos de prova}

A avaliação da resistência mecânica das argamassas (industrializadas e mistas) reforçadas utilizadas nos revestimentos foi realizada comparando-as com as propriedades mecânicas das argamassas sem reforço (argamassa de referência). A mistura da argamassa foi realizada de acordo com a NBR 13276 (ABNT, 2005c), e a cura dos corpos de prova ocorreu em temperatura ambiente até a idade de 28 dias. Todos os ensaios foram executados utilizando uma máquina de ensaios universal de marca Instron, modelo 1000HDX, com capacidade de carga de $1.000 \mathrm{kN}$.

\section{Resistência à compressão axial}

Esse ensaio tem por objetivo avaliar a influência da tela no desempenho mecânico das argamassas por meio de um carregamento contínuo de compressão. Para tanto, foram utilizadas telas com a mesma altura do corpo de prova $(20 \mathrm{~cm})$ e comprimento de circunferência de aproximadamente $18,8 \mathrm{~cm}$, de forma a obter um cobrimento de $2 \mathrm{~cm}$ no corpo de prova, levando em consideração a maior espessura da camada de argamassa mista aplicada nos painéis, conforme apresenta a Figura 3. 
Figura 3 - Posicionamento da tela nos ensaios de resistência mecânica

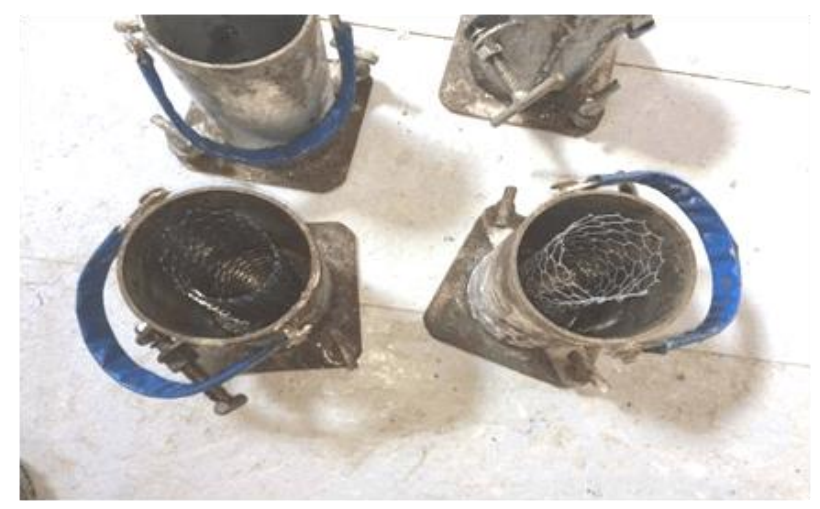

Primeiramente, as telas foram colocadas nos corpos de prova e, em seguida, estes foram adensados conforme a NBR 7215 (ABNT, 1997). Ao total foram produzidos 16 corpos de prova para cada tipo de argamassa (industrializada e mista), sendo 4 para cada tipo de tela inserida na argamassa e 4 para argamassa de referência, ensaiados de acordo com a norma NBR 5739 (ABNT, 2007).

\section{Resistência à tração por compressão diametral}

Foi moldada a mesma quantidade de corpos de prova do ensaio de compressão axial, inserindo-se a tela na metade do corpo de prova (Figura 4) e seguindo as recomendações da NBR 7222 (ABNT, 2011).

\section{Resistência à flexão}

Ao total foram moldados três corpos de prova prismáticos de dimensões 7,5x7,5x28,5 cm para cada tipo de argamassa com tela e de argamassa de referência na avaliação da resistência à flexão.

A moldagem foi executada em quatro camadas, adensando manualmente cada uma delas com trintagolpes por meio de um soquete. Após colocar a primeira camada de argamassa a um terço da altura do corpo de prova e adensá-la, foi inserida a tela com as mesmas dimensões do corpo de prova e apertada manualmente (Figura 5). Em seguida, as camadas restantes foram colocadas e adensadas para engavetar a tela e retirar possíveis bolhas. Esse ensaio foi realizado com base nas recomendações da NBR 13279 (ABNT, 2005f) com velocidade de carregamento de $0,05 \mathrm{kN} / \mathrm{s}$.

\section{Resistência ao cisalhamento}

Para estudar a ação cisalhante das argamassas contendo as três diferentes telas em estudo, foram utilizados 2

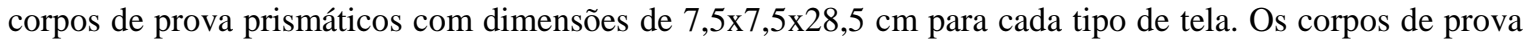
foram preenchidos e adensados conforme os procedimentos do ensaio de flexão, no entanto a tela foi introduzida no corpo de prova a um meio de sua altura.

Como não existe norma brasileira para execução do ensaio de cisalhamento, esse ensaio foi realizado conforme a metodologia desenvolvida por Pinto et al. (2016). Na idade de 28 dias de cura ambiente, os corpos de prova foram cortados em um equipamento de retífica a fim de se obter o total de 4 corpos de prova de 7,5x7,5x10 cm para cada tipo de reforço, submetendo-os a carregamento constante com velocidade de 0,1 $\mathrm{mm} / \mathrm{s}$ durante o ensaio (Figura 6).

\section{Avaliação da incidência de fissuração}

De modo a avaliar o comportamento do sistema de vedação vertical quando submetido a variação de temperatura, a NBR 15575-4 (ABNT, 2013a) recomenda um método de ensaio para analisar a ocorrência de fissuras e/ou falhas que possam comprometer o desempenho desse sistema, durante e após ciclos sucessivos de calor e resfriamento. O ensaio é realizado com a utilização de um painel radiante capaz de fornecer uma temperatura superficial de $80{ }^{\circ} \mathrm{C}$ (controlada com termopares) na superfície de um painel de alvenaria de $1,20 \mathrm{~m}$ de comprimento e altura equivalente ao pé-direito da edificação, com os detalhes do sistema de revestimento executados. Para tanto, ambos os painéis são posicionados paralelamente durante $1 \mathrm{~h}$, promovendo-se, em seguida, o resfriamento via jato de água (simulação da chuva) até atingir a temperatura

472 Musse, D. S.; Coelho, V. A.; Gonçalves, J. P.; Silva, F. G. S. 
superficial de $20^{\circ} \mathrm{C}$. Esse processo é repetido em dez ciclos sucessivos, analisando-se as degradações no revestimento.

Silva e Bauer (2009) aplicaram um carregamento térmico em argamassas utilizando um painel contendo seis lâmpadas de $250 \mathrm{~W}$ e um ventilador com o intuito de simular condições de agressividade ambiental (insolação e vento) e produzir um excesso de fissuração na superfície do revestimento utilizando argamassas mistas com excesso de cimento, de cal e de agregado.

Com base nessas metodologias, foram confeccionados nesta pesquisa três painéis de alvenaria com área de $0,49 \mathrm{~m}^{2}$ para aplicação da argamassa armada para cada uma das três telas selecionadas e um painel de referência (sem reforço) para comparação dos resultados.

Figura 4 - Detalhe da posição da tela para ensaio de compressão diametral

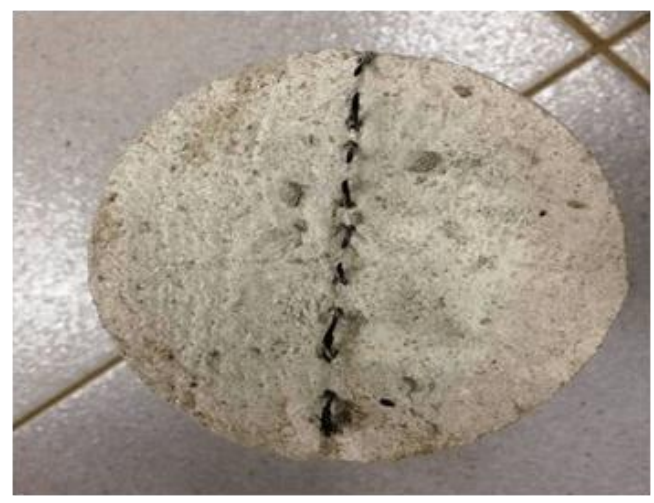

Figura 5 - Tela inserida sobre a primeira camada de argamassa, localizada a um terço da altura do corpo de prova prismático

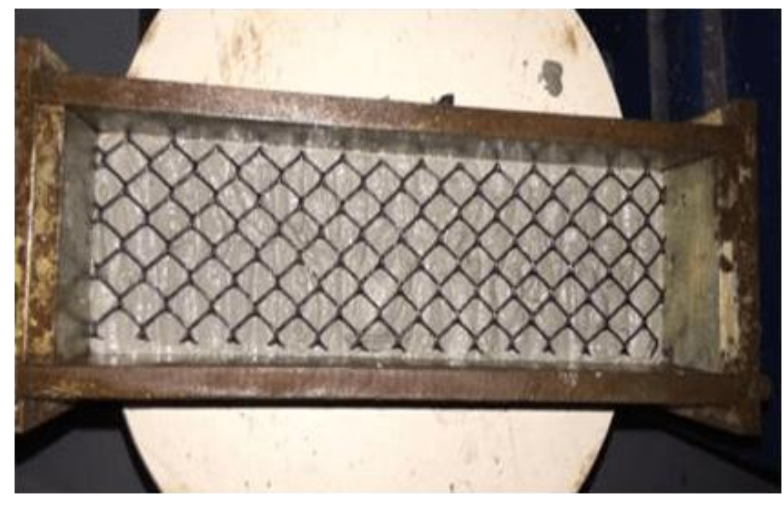

Figura 6 - Ensaio de cisalhamento

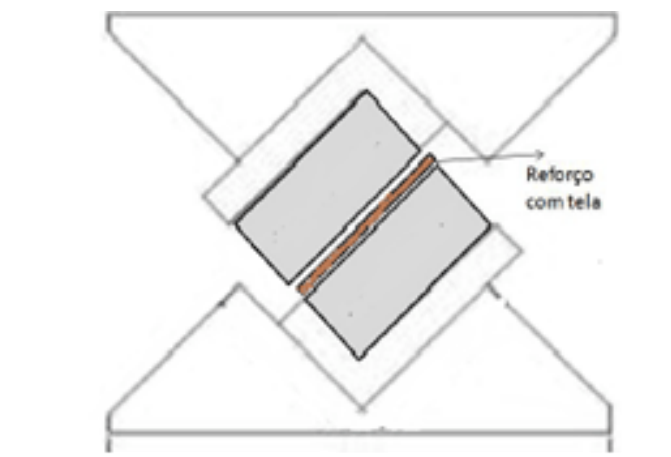

(a) Posição da tela no ensaio (PINTO et al., 2016)

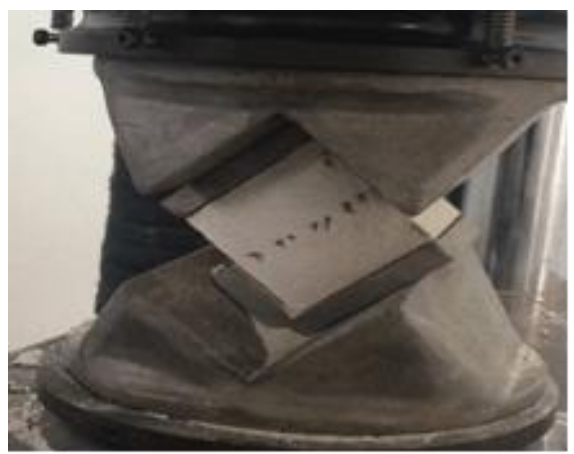

(b) Detalhe do ensaio de cisalhamento 
Foram utilizados os dois lados dos painéis: um com tratamento de base com chapisco rolado industrializado, com espessura de revestimento de $2,5 \mathrm{~cm}$, e outrosem o tratamento da base, face destinada à camada do revestimento com espessura de $5 \mathrm{~cm}$. Essas diferentes espessuras permitiram a análise do comportamento das telas em duas diferentes temperaturas de exposição: carregamento térmico de $38{ }^{\circ} \mathrm{C}$ e de $80^{\circ} \mathrm{C}$.

\section{Revestimentos reforçados com tela submetidos ao carregamento térmico de $38^{\circ} \mathrm{C}$}

Para cada tipo de tela, foi confeccionado um painel em que, após o intervalo de cura do chapisco, foram instaladas molduras de madeira com espessuras de $2,5 \mathrm{~cm}$ visando garantir a mesma espessura do reboco em toda a superfície. A aplicação do revestimento ocorreu em duas camadas de argamassa mista. A primeira camada foi aplicada com $1 \mathrm{~cm}$ de espessura, comprimida e alisada, seguida da instalação da tela por meio de amarração com aço e pinos galvanizados; e a segunda camada de argamassa de 1,5 cm de espessura foi aplicada.

Logo após a finalização do reboco, os revestimentos foram submetidos a um carregamento térmico por meio de um painel artificial constituído de seislâmpadas incandescentes com potência total de $600 \mathrm{~W}$, durante 45 min para alcançar aproximadamente $38^{\circ} \mathrm{C}$ de temperatura na superfície do revestimento. A Figura 7 ilustraa execução do processo.

O acompanhamento da variação de temperatura na superfície do material foi realizado com um termômetro digital de superfície com mira alaser;já a temperatura ambiente e a umidade relativa do ar foram acompanhadas com um termo-higrômetro digital.

\section{Revestimento reforçado com tela com aplicação do carregamento térmico de $80{ }^{\circ} \mathrm{C}$}

A aplicação do revestimento na face sem tratamento de base seguiu as mesmas etapas citadas anteriormente, no estudo do carregamento térmico de $38^{\circ} \mathrm{C}$. No entanto, o revestimento foi realizado com duas camadas de argamassa, sendo a primeira com espessura de $3 \mathrm{~cm}$, utilizando argamassa industrializada, seguida da colocação da tela e da segunda camada, de espessura de $2 \mathrm{~cm}$, com argamassa mista, totalizando um reboco de $5 \mathrm{~cm}$ de espessura.

Figura 7 - Etapas de execução do revestimento

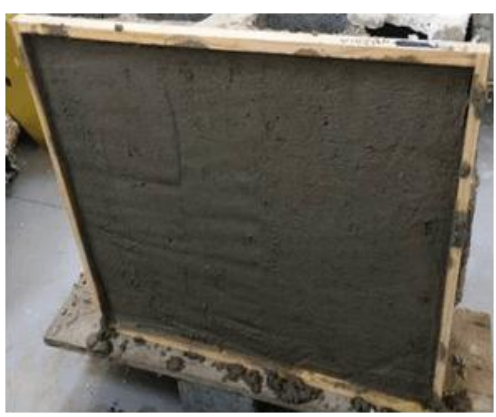

(a) Primeira camada de argamassa

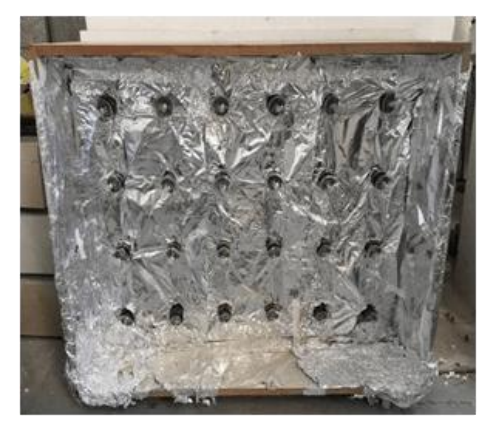

(d) Painel térmico



(b) Instalação da tela



(e) Instalação do painel térmico paralelamente à alvenaria



(c) Revestimento acabado e sarrafeado



(f) Isolamento dos painéis com isopor revestido com papel-alumínio

474 Musse, D. S.; Coelho, V. A.; Gonçalves, J. P.; Silva, F. G. S. 
Para este estudo foi necessário utilizar o total de 24 lâmpadas incandescentes de $100 \mathrm{~W}$ no painel térmico para alcançar aproximadamente $80{ }^{\circ} \mathrm{C}$ de temperatura na superfície, conforme a NBR 15575-4 (ABNT, 2013a), porém em um período de 2 h e 30 min de exposição.

\section{Análise termográfica}

A técnica termogravimétrica se baseia na transferência de calor entre corpos ou entre um corpo e o ambiente pelo mecanismo de radiação. Essa radiação é transformada em pulsos elétricos em uma câmara termográfica, formando imagens digitais com escala de temperatura que podem ser analisadas com softwares (ALTOÉ; OLIVEIRA FILHO, 2012). Tal técnica apresenta a vantagem de não provocar nenhuma destruição na estrutura, reduzindo o tempo e a quantidade de trabalho, porém não definea profundidade e a espessura da fissura (MENDONÇA, 2005).

Esse método não destrutivo abrange uma elevada quantidade de variáveis que permitem analisar os dados para inspecionar as patologias, no entanto, como o equipamento capta variações térmicas de superfície, as imagens dependem das características físicas e térmicas do objeto a ser avaliado, podendo sofrer influência de fatores que podem alterar a temperatura e dificultar a interpretação dos termogramas (BAUER; PAVÓN, 2015).

Nesse contexto, a análise termográfica foi aplicada nesta pesquisa imediatamente após a remoção do painel térmico. Realizou-se a análise por termografia infravermelha de forma qualitativa, analisando-se os diferentes pontos quentes e frios nos termogramas, e de forma quantitativa, por meio da análise do método Delta T, que consiste em acompanhar a diferença de temperatura entre as regiões defeituosas e uma sem defeito (BAUER et al., 2016). Para tanto, foi utilizada uma câmera infravermelha profissional (Flir C2), na faixa de temperatura de $-10{ }^{\circ} \mathrm{C}$ a $150{ }^{\circ} \mathrm{C}, 2 \%$ de precisão, faixa espectral de $7,5 \mu$ ma $14 \mu \mathrm{m}$, resolução de $320 \times 240$ pixels e IFOV de $11 \mathrm{mrad}$.

Contudo, para capturar as imagens, a emissividade utilizada foi de 0,95 , determinada pelo método prescrito pela E1933 (AMERICAN..., 1999). A temperatura refletida foi fixada em $32{ }^{\circ} \mathrm{C}$, e a umidade relativa encontrada por meio de um termo-higrômetro digital foi de $80 \%$, sendo este valor característico para a região de Salvador, BA. Feito isso, as imagens termográficas foram realizadas com a câmera posicionada a um ângulo de $45^{\circ}$ e a $1,50 \mathrm{~m}$ de distância em relação aos painéis imediatamente após a remoção do painel térmico (durante o resfriamento). A captura das imagens ocorreu a cada intervalo de 30min, até a estabilização térmica do painel em relação à temperatura ambiente.

\section{Mapeamento e índice de fissuração dos painéis}

O comprimento e a abertura das fissuras foram monitorados desde o surgimento até a idade de 28 dias, com o auxílio de um fissurômetro.

Passadaa idade de cura, o mapeamento das fissuras foi realizado de acordo com Silva e Bauer (2009), mediante a identificação visual das fissuras com marcação de giz de cera para identificar a trajetória delas. Além disso, o comprimento das fissuras foi medido com o auxílio de um barbante e de uma régua graduada. Para tanto, a intensidade das fissuras foi definida por meio da soma dos comprimentos delas em todas as direções ocorridas dividida pela área do painel, com resultado expresso em metro por metro quadrado. As etapas deste estudo podem ser observadas na Figura 8.

\section{Avaliação da eficiência do tipo de reparo das fissuras}

As fissuras dos revestimentos armados com espessuras de $5 \mathrm{~cm}$ de reboco foram recuperadas com massa acrílica com telas de poliéster e resina epóxi (Compound Adesivo TIX). Na recuperação das fissuras dos painéis, estes foram divididos em duas partes para a aplicação dos dois métodos construtivos. As etapas para recuperação das fissuras com massa acrílica e tela adotada neste trabalho são descritas na Figura 9.

Com o objetivo de analisar o tipo de recuperação em ambientes expostos a elevadas temperaturas, os revestimentos após 14 dias de recuperados foram submetidos a um carregamento térmico de $38{ }^{\circ} \mathrm{C}$, simulando as condições naturais de temperatura local, resfriados por $24 \mathrm{~h}$ em temperatura ambiente e reaquecidos com temperatura de $80^{\circ} \mathrm{C}$, padronizando as mesmas temperaturas utilizadas na avaliação da incidência de fissuração. 
Figura 8 - Etapas do mapeamento das fissuras

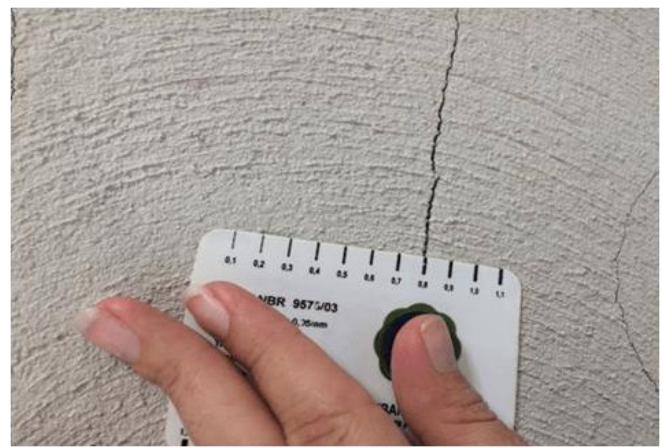

(a) Medida da espessura com fissurômetro



(c) Aferição do comprimento com o auxílio do barbante

Figura 9 - Etapas de recuperação das fissuras

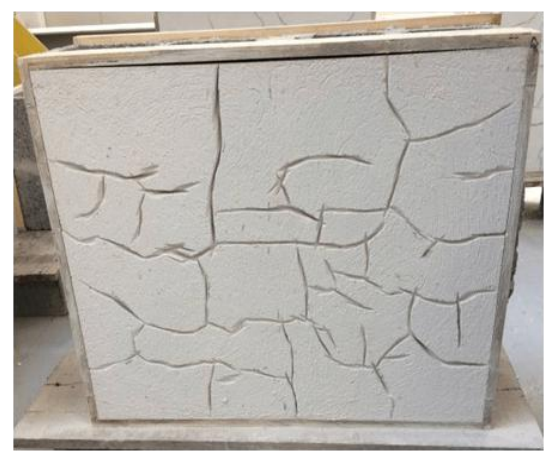

(a) Abertura dos sulcos

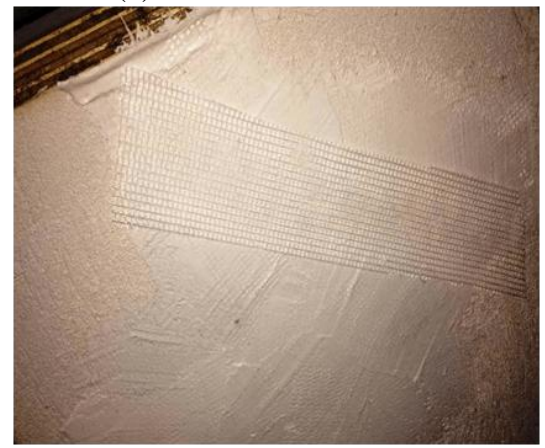

(c) Instalação da tela de poliéster

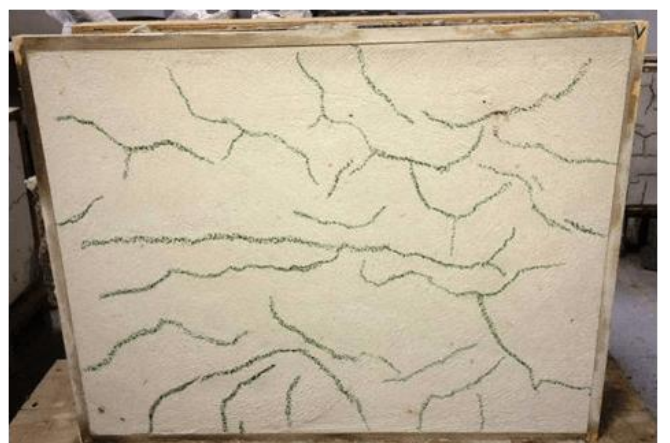

(b) Mapeamento das fissuras com giz de cera

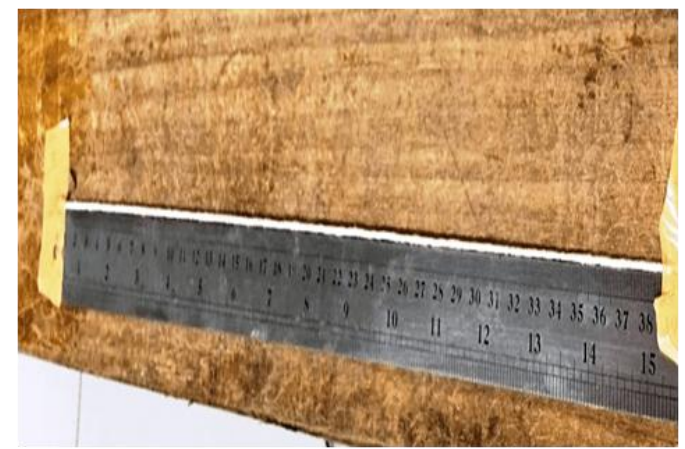

(d) Medida do comprimento do fio de barbante com régua graduada

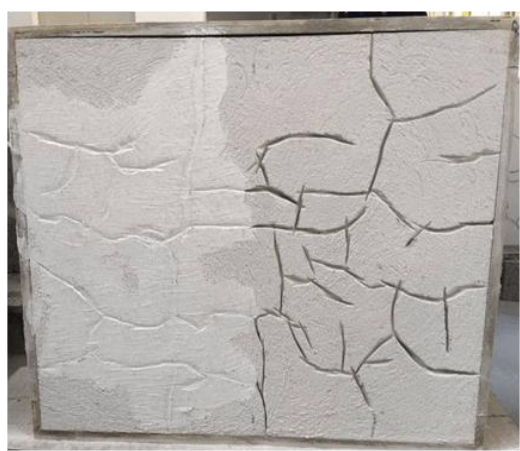

(b) Preenchimento dos sulcos com massa acrílica

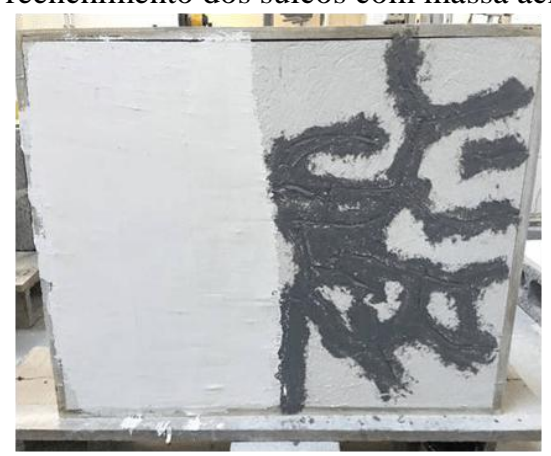

(d) Acabamento final com aplicação das útimas camadas de massa acrílica e preenchimento dos sulcos com resina epóxi 
A análise foi realizada de forma qualitativa, avaliando-se o aparecimento de fissuras e desplacamentos no revestimento. Além disso, para melhor observação, imagens termográficas foram realizadas.

\section{Avaliação do comportamento quando submetido a impacto}

Esse ensaio foi realizado com basenas recomendações da NBR 15575-2 (ABNT, 2013b). O experimento foi executado apenas nos revestimentos de argamassa mista com espessura de $2,5 \mathrm{~cm}$ submetidos ao carregamento térmico de $38{ }^{\circ} \mathrm{C}$. Desse modo, os painéis foram deitados sobre uma camada de $5 \mathrm{~cm}$ de areia, para então uma esfera de aço maciça com massa de $1 \mathrm{~kg}$ ser lançada em queda livre em determinada altura por dez vezes consecutivas. A esfera de aço utilizada é apresentada na Figura 10, enquanto a Tabela 3 apresenta as alturas e as energias empregadas.

Para garantir a mesma altura de lançamento da esfera, o ensaio foi executado utilizando-se um suporte com a altura padronizada de lançamento. Além disso, o mesmo operador lançou a esfera. Após cada queda da esfera, foi realizada a medição das profundidades das mossas com um paquímetro, observando também falhas como fissuras, destacamentos e ruínas. A Figura 11 ilustraa execução do ensaio de impacto e a medição das profundidades.

Figura 10 - Esfera maciça do ensaio de impacto

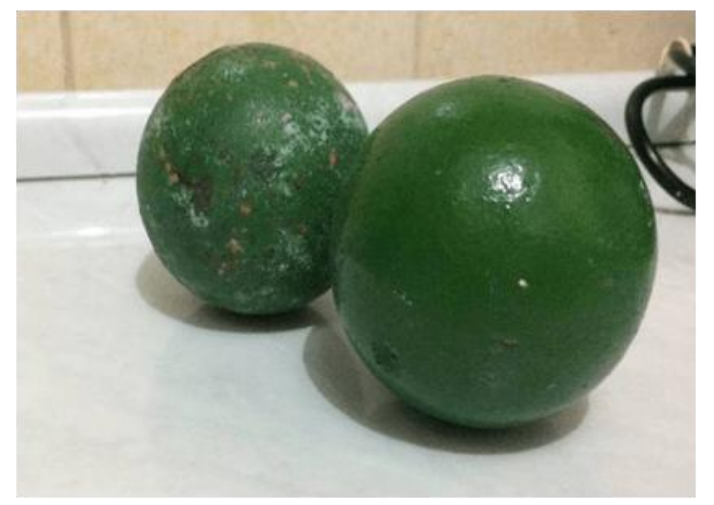

Tabela 3 - Altura de lançamento das esferas com suas respectivas energias

\begin{tabular}{c|c|c|c}
\hline Impacto & Massa (kg) & Altura (m) & Energia (J) \\
\hline \multirow{2}{*}{ Aplicação de 10 impactos de corpo rígido } & 1,00 & 2,00 & 20 \\
& 1,00 & 1,00 & 10 \\
\hline
\end{tabular}

Figura 11 - Ensaio de corpo rígido

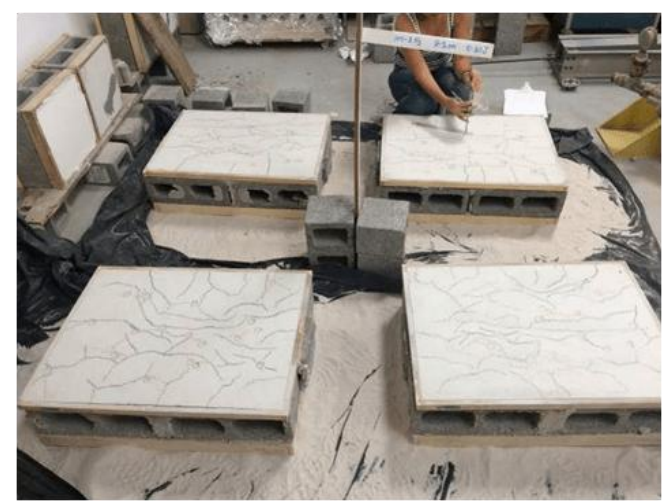

(a) Alvenaria sobre uma camada de areia

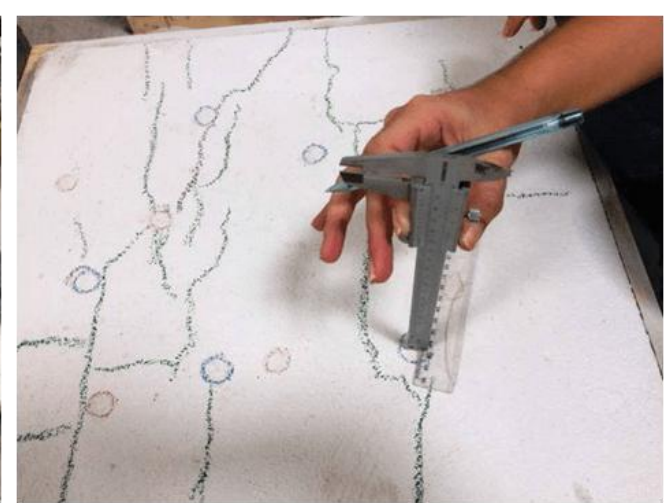

(b) Medição das mossas de cada impacto 


\section{Resultados e discussões}

\section{Avaliação mecânica das argamassas armadas em corpos de prova}

As análises mecânicas das argamassas estudadas (industrializada e mista) obtiveram resultados análogos, conforme apresenta o Quadro 1.

As argamassas mistas obtiveram menores resistências em comparação às argamassas industrializadas, devido àmaior quantidade de finos na composição e elevada relação água-cimento $(\mathrm{a} / \mathrm{c})$. No entanto, foi observado que as características da argamassa podem interferir nos resultados, prejudicando a impregnação da tela com argamassa ao se trabalhar com telas de menores aberturas de malha (tela 2 e tela 3 ).

Os dados mostram que os três tipos de telas utilizadas para reforçar a argamassa promoveram diminuição da resistência à compressão axial. Comparando com a argamassa industrializada não armada, esse decréscimo da resistência foi de 3,03\% para a tela 1 , de 7,52\% para a tela 2 e de $8,77 \%$ para a tela 3. Já para a argamassa mista,a redução em relação à argamassa mista não armada foi de 7,94\% para atela 1, de 13,51\% para a tela 2 e de $28,52 \%$ para a tela 3 .

Notou-se que a posição da tela pode ter modificado o comportamento mecânico do ensaio, diminuindo a resistência à compressão em todas as argamassas reforçadas devido à formação de defeitos na argamassa. Considerando que as telas em formato cilíndrico foram inseridas na camada de argamassa com $2 \mathrm{~cm}$ de cobrimento da fôrma, isso resultou no encapsulamento de uma parte da argamassa e na fragilidade da argamassa da parte externa a essa armação. Dessa forma, a tela restringiu a ruptura do corpo de prova, uma vez que esse ensaio rompe por tração na região central. O estudo corrobora as análises de Gomes, Neves e Souza (2007), que constataram que o uso de telas em corpos de provas cilíndricos é mais eficiente quando posicionadas próximo à superfície.

Quanto aos resultados da resistência à compressão por compressão diametral, nota-se que as argamassas industrializadas reforçadas com telas obtiveram pequena redução na resistência, de 4,14\%, 7,79\% e 19,49\% para a tela 1, a tela 2 e a tela 3 respectivamente.As inserções das telas para reforçar as argamassas mistas tiveram o mesmo comportamento das argamassas industrializadas armadas. A argamassa com a tela 1 teve uma resistência por compressão diametral $6,58 \%$ menor que a sem tela, seguida da tela 2, com 8,54\%, e da tela 3 , com 16,13\%.Analisando a ruptura dos corpos de prova armados com tela, notou-se que a tela, ao ser inserida no plano de ruptura de tração, gerou uma zona de transição, diminuindo a resistência das argamassas. Assim, a perda de resistência é atribuída ao fato de o conjunto argamassa-tela ser menos homogêneo, ocasionando interferência na junção entre camadas de argamassa e efeito de corte cisalhante, principalmente com a tela 3 , que possui menor abertura de malha e fios entrelaçados.

\section{Quadro 1 - Resumo dos resultados de resistência mecânica}

\begin{tabular}{c|c|c|c|c|c|c|c|c}
\hline \multirow{2}{*}{$\begin{array}{c}\text { Propriedades } \\
\text { mecânicas }\end{array}$} & \multicolumn{4}{|c|}{ Argamassa industrializada } & \multicolumn{4}{c}{ Argamassa mista } \\
\cline { 2 - 9 } & $\begin{array}{c}\text { Sem } \\
\text { Tela }\end{array}$ & $\begin{array}{c}\text { Tela } \\
1\end{array}$ & $\begin{array}{c}\text { Tela } \\
2\end{array}$ & $\begin{array}{c}\text { Tela } \\
3\end{array}$ & $\begin{array}{c}\text { Sem } \\
\text { tela }\end{array}$ & $\begin{array}{c}\text { Tela } \\
1\end{array}$ & $\begin{array}{c}\text { Tela } \\
2\end{array}$ & $\begin{array}{c}\text { Tela } \\
3\end{array}$ \\
\hline $\begin{array}{c}\text { Compressão axial } \\
(\mathrm{MPa})\end{array}$ & 7,40 & 7,18 & 6,85 & 6,75 & 1,38 & 1,27 & 1,19 & 0,99 \\
\hline $\begin{array}{c}\text { Tração por comp. } \\
\text { diametral (MPa) }\end{array}$ & 0,42 & 0,40 & 0,38 & 0,33 & 0,06 & 0,06 & 0,06 & 0,05 \\
\hline Flexão $(\mathrm{MPa})$ & 1,18 & 1,61 & 1,71 & 1,78 & 0,50 & 0,74 & 0,73 & 0,61 \\
\hline Cisalhamento $(\mathrm{MPa})$ & 4,20 & 4,18 & 4,13 & 4,17 & 1,76 & 1,73 & 1,24 & 1,29 \\
\hline
\end{tabular}

478 Musse, D. S.; Coelho, V. A.; Gonçalves, J. P.; Silva, F. G. S. 
A resistência média à tração na flexão das argamassas industrializadas reforçadas com tela galvanizada de malha hexagonal (tela 3)supera as argamassas de referência em até 50,29\%. As argamassas com tela 1 e tela 2 obtiveram aumento de 36,29\% e de 42,29\% respectivamente em relação à argamassa sem tela (referência). Semelhantemente ao ocorrido nas argamassas industrializadas, houve incremento na resistência à flexão das argamassas mistas armadas. Comparando as resistências encontradas, percebe-se que as telas proporcionaram aumento de 47,63\%, 46,67\% e 22,73\% nas argamassas mistas armadas com tela 1, tela 2 e tela 3 respectivamente. Os achados de Schimelfenig et al. (2018) também indicaram aumento de resistência significativo em relação às demais telas utilizadas como reforço de argamassa industrializada em corpos de prova prismáticos, porém estatisticamente igual àreferência (sem tela). Naquele estudo, a tela hexagonal apresentou baixo desempenho quando comparada com a eletrossoldada. De acordo com os autores, as características do fio e a grande deformação da tela eletrossoldadasugeremsemelhança do módulo de deformação dela com o módulo de deformação da argamassa, uma vez que essa tela é incapaz de suportar os esforços causados pela tração na flexão do sistema.

É possível observar que a inserção das telas promoveu perda na resistência ao cisalhamento. Nota-se que a inserção da tela entre as camadas de argamassa não garantiu a completa junção dos materiais; consequentemente, a tela se comportou como um elemento divisório das camadas, prejudicando a aderência e diminuindo a área resistente da argamassa. As análises mecânicas das argamassas estudadas (industrializada e mista) obtiveram resultados análogos. As argamassas mistas obtiveram menores resistências em comparação às argamassas industrializadas, devido àmaior quantidade de finos na composição e elevada relação a/c. No entanto, foi observado que as características da argamassa podem interferir nos resultados, prejudicando a impregnação da tela com argamassa ao se trabalhar com telas de menores aberturas de malha (tela 2 e tela 3 ).

Com base nos resultados apresentados, observa-se, como esperado, que somente no ensaio de resistência à tração na flexão as telas conceberam reforço nas argamassas. Isso pode ser explicado devido ao fato de a tela ter sido inserida na região das tensões de tração, aumentando a resistência.

Portanto, conforme apresentado nesta etapa, os resultados de tração na flexão reforçam os encontrados por Antunes e Masuero (2016), confirmando as telas como elemento de reforço.

\section{Avaliação da incidência de fissuras em revestimentos reforçados com telas Efeito do carregamento térmico de $38^{\circ} \mathrm{C}$}

\section{Análise termográfica}

A inspeção visual dos revestimentos permitiu a identificação de fissuras ramificadas em todos os painéis. No Quadro 2 é possível observar os termogramas obtidos a partir do ensaio termográfico, referentes às imagens térmicas logo após a retirada do painel e após $3 \mathrm{~h}$ de resfriamento. Nos termogramas do revestimento sem tela, notou-se a presença de fissuras nos pontos de maiores temperaturas logo após a retirada do carregamento térmico, desaparecendo nas imagens após 60 min do resfriamento;no entanto, os defeitos dos revestimentos reforçados com telas não foram identificados nas imagens.

A evolução do comportamento térmico das fissuras foi observadapor meio da variação das temperaturas (Delta T) dos pontos com fissuras identificadas visualmente (sp1, sp2 e sp3) em relação ao ponto sem defeitos (sp4), indicados nos termogramas do Quadro 2.

Essas variações de temperatura (Delta Ts) apresentaram resultados mais relevantes nas três primeiras leituras, conforme apresenta a Tabela 4.

De acordo com os resultados, o Delta $\mathrm{T}$ máximo dos revestimentos sem tela nos pontos que apresentaram fissuras foi visualizado com nitidez, apresentando valores de $1,8{ }^{\circ} \mathrm{C}, 1,3{ }^{\circ} \mathrm{C}$ e $0,9^{\circ} \mathrm{C}$, para sp1, sp2 e sp3 respectivamente.

Apesar de apresentar máximos valores de Delta $\mathrm{T}$ na primeira leitura do termograma de $1,5^{\circ} \mathrm{C}, 1,7{ }^{\circ} \mathrm{C}$ e 1,2 ${ }^{\circ} \mathrm{C}$ respectivamente, os painéis com reforçocomtela 1, tela 2 e tela 3 não permitiram a identificação dos defeitos nas imagens (Quadro 2). Por meio da avaliação qualitativa, as fissuras visualizadas e identificadas como sp1, sp2 e sp3 apresentaram maiores temperaturas, sendo a região sem defeito (sp4) a mais fria. 
Quadro 2 - Termogramas dos revestimentos submetidos ao carregamento térmico de $38^{\circ} \mathrm{C}$

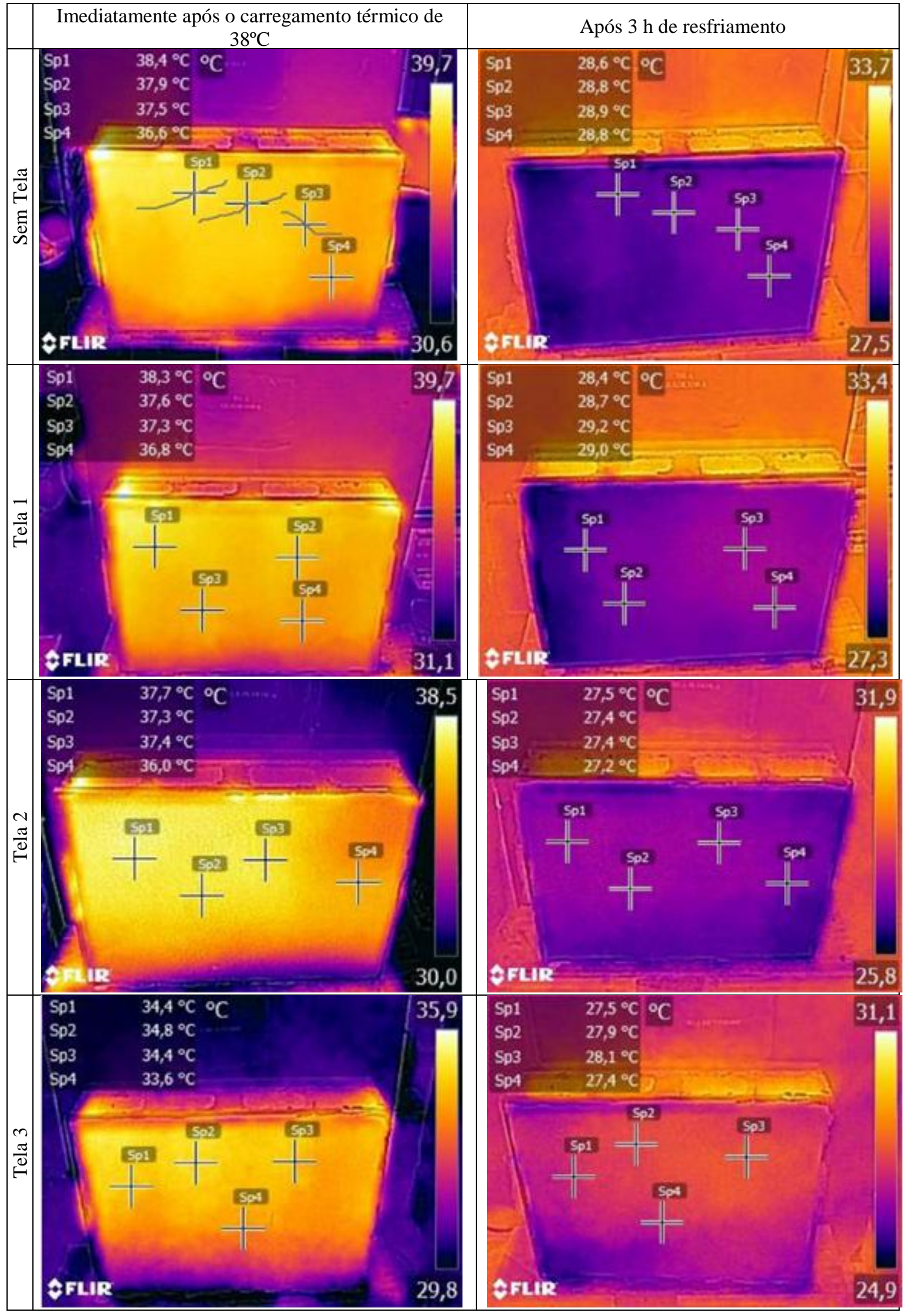

480 Musse, D. S.; Coelho, V. A.; Gonçalves, J. P.; Silva, F. G. S. 
De modo geral, a Tabela 4 apresenta valores de Delta $\mathrm{T}$ abaixo de $1,8{ }^{\circ} \mathrm{C}$, ou seja, ao decorrer do resfriamento, sem ação da fonte de calor, o fluxo térmico diminui e as temperaturas das zonas que fissuraram se aproximaram das temperaturas dos pontos sem defeito. Esse fato foi observado principalmente nos termogramas realizados após $3 \mathrm{~h}$ de resfriamento (Quadro 2), ocorrendo o equilíbrio da temperatura dos painéis com a temperatura ambiente.

A dificuldade de identificação dos defeitos pode ser explicada pela tipologia das fissuras nos revestimentos dos painéis, levando em consideração sua profundidade. Esse fato confirma os encontrados nos estudos de termografia passiva tratada de forma quantitativa de Bauer e Pávon (2016), em que em determinada região com fissuras ramificadas desorganizadas, as temperaturas com defeito são muito próximas da região íntegra, ou seja, com Delta $\mathrm{T}$ de menor valor. Isso dificulta a medição e a interpretação dos termogramas, sendo necessária a adequação de critérios para a identificação das patologias por meio de ajustes de fluxo de calor.

\section{Mapeamento e índice de fissuração dos painéis}

Para melhor identificar a incidência de fissuras nos revestimentos na idade de 28 dias, molhou-se a superfície do revestimento com borrifador e, em seguida, realizou-se o contorno das fissuras por meio de um giz de cera. A avaliação do carregamento térmico na temperatura de $38^{\circ} \mathrm{C}$ e o efeito das três diferentes telas no combate à fissuração devido à retração inicial nos painéis revestidos com espessura de $2,5 \mathrm{~cm}$ de argamassa podem ser observados na Figura 12.

A argamassa mista utilizada no revestimento possui emsua composição elevado teor de finos e cal em excesso, os quais, em conjunto, prejudicam o desempenho do revestimento, provocando fissuras. Além disso, o carregamento térmico aplicado logo após a execução do revestimento favorece ainda mais a formação dessas fissuras, por conta da elevada perda de água por evaporação da argamassa. Observa-se na Figura 12 que todos os painéis obtiveram fissuras mapeadas e não orientadas, que são características do tipo de fissuração por retração. Esse fato é similar ao observado na pesquisa de Silva e Bauer (2009), naqual os resultados apontaram para o aumento na formação de fissuras com a aplicação do efeito térmico e do vento.

A tela 1 aplicada no reforço do revestimento promoveu melhores resultados na distribuição de esforços, devido ao aparecimento de menores aberturas de fissuras $(0,3 \mathrm{~mm}$ e $0,1 \mathrm{~mm})$ e de redução de $7,51 \%$ no índice de fissuração comparada com o revestimento sem tela. Já a tela 2 obteve índice de fissuração de 13,02 $\mathrm{mm} / \mathrm{m}^{2}$, cerca de $14,16 \%$ superior ao valor encontrado para os revestimentos sem reforço. Além disso, a abertura encontrada foi de $0,7 \mathrm{~mm}$, enquanto os revestimentos sem reforço apresentaram espessuras de 0,8 $\mathrm{mm}$ e índice de fissuração de $11,49 \mathrm{~mm} / \mathrm{m}^{2}$.

Para o reforço ocorrido com a tela 3 , o índice de fissuração foi de $23,17 \%$ superior em relação ao de referência. No entanto, as fissuras adquiridas tiveram espessuras médias de 0,4 mm, ou seja, conseguiu-se distribuir as tensões, promovendo aumento do índice de fissuras, porém com menores aberturas devido àmenor abertura da malha dessa tela.

\section{Efeito do carregamento térmico de $80^{\circ} \mathrm{C}$}

\section{Análise termográfica}

De forma similar àanálise dos termogramas realizados anteriormente, os termogramas obtidos a partir do ensaio termográfico referentes às imagens térmicas após a retirada do painel térmico são apresentados no Quadro 3. Como esperado, os revestimentos em questão apresentaram resfriamento mais lento devido à aplicação de maior carregamento térmico.

Os termogramas dos revestimentos sem tela permitiram a identificação das fissuras logo após a remoção do painel térmico, conforme indicado no Quadro 3. No entanto, ao longo do resfriamento houve pequena perda de nitidez dos defeitos devido à diminuição do gradiente térmico. Nos revestimentos reforçados não foi possível identificar as fissuras. As imagens mostraram as regiões mais quentes e mais frias de acordo com a escala, porém apresentaram distorções que inviabilizaram a mensuração qualitativa das fissuras.

Comparando esses termogramas com os da etapa anterior em revestimentos sem tela, observa-se que, para uma temperatura mais elevada, a nitidez do defeito torna-se melhor, facilitando a identificação das fissuras nos termogramas.

Considerando os pontos com fissuras identificadas visualmente (sp1, sp2 e sp3) em relação ao ponto sem defeitos (sp4) indicados nos termogramas do Quadro 2, foi analisado o Delta Tpara avaliação dos danos. 
Igualmente nos termogramas com carregamento térmico de $38^{\circ} \mathrm{C}$, os resultados foram representativos nas três primeiras leituras, conforme apresenta a Tabela 5 .

Nos revestimentos sem reforço de tela, durante um resfriamento com menor velocidade de queda, ao contrário do estudo anterior, as fissuras puderam ser observadas até mesmo com o equilíbrio térmico do revestimento com a temperatura ambiente, em queo Delta $\mathrm{T}$ mínimo foi abaixo de $0,5^{\circ} \mathrm{C}$. Já nos painéis reforçados com astelas 1 e 3, o gradiente térmico de aproximadamente $7{ }^{\circ} \mathrm{C}$ não possibilitou a identificação dos defeitos nesses painéis. A eficiência do reforço promovido por esses dois tipos de telas pode ter absorvido uma parcela das tensões ocorridas devido ao carregamento térmico, distribuindo as tensões em toda a área do painel e criando fissuras superficiais com menores espessuras.

Contudo, notou-se que as variações de Delta Ts, profundidade das fissuras, carregamento térmico aplicado, tal como o ambiente de realização da análise, são fatores que influenciaram na visualização dos defeitos, já que foram aplicadas as mesmas condições de contorno em todo o estudo.

Tabela 4 - Evolução do DeltaT nos primeiros momentos do resfriamento dos painéis submetidos ao carregamento térmico de $38^{\circ} \mathrm{C}$

\begin{tabular}{|c|c|c|c|c|c|c|c|c|c|c|c|c|}
\hline \multirow{3}{*}{ Leitura } & \multicolumn{12}{|c|}{ Delta $\mathrm{T}\left({ }^{\circ} \mathrm{C}\right)$} \\
\hline & \multicolumn{3}{|c|}{ Sem tela } & \multicolumn{3}{|c|}{ Tela 1} & \multicolumn{3}{|c|}{ Tela 2} & \multicolumn{3}{|c|}{ Tela 3} \\
\hline & sp1 & sp2 & sp3 & sp1 & sp2 & sp3 & sp1 & sp2 & sp3 & sp1 & sp2 & sp3 \\
\hline Inicial & 1,8 & 1,3 & 0,9 & 1,5 & 0,8 & 0,5 & 1,7 & 1,3 & 1,4 & 0,8 & 1,2 & 0,8 \\
\hline $30 \mathrm{~min}$ & 1,0 & 0,8 & 0,8 & 0,8 & 0,3 & 0,7 & 1,1 & 0,6 & 0,7 & 1,1 & 1,2 & 1,0 \\
\hline $60 \mathrm{~min}$ & 0,6 & 0,7 & $\mathbf{0 , 8}$ & 0,3 & 0,3 & 0,4 & 0,7 & 0,7 & 0,5 & 1,2 & 1,3 & 1,3 \\
\hline
\end{tabular}

Figura 12 - Análise do carregamento de $38^{\circ} \mathrm{C}$ e o efeito da tela no combate à fissuração dos revestimentos com espessura de argamassa de $2,5 \mathrm{~cm}$

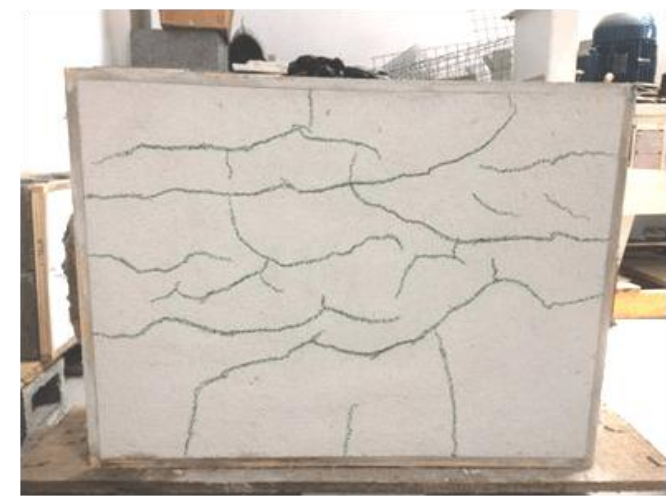

(a) Sem tela

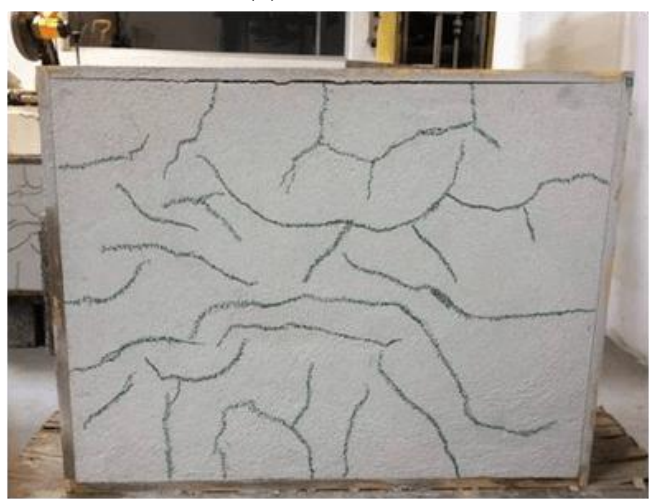

(c) Reforço tela 2- Tela de polietileno

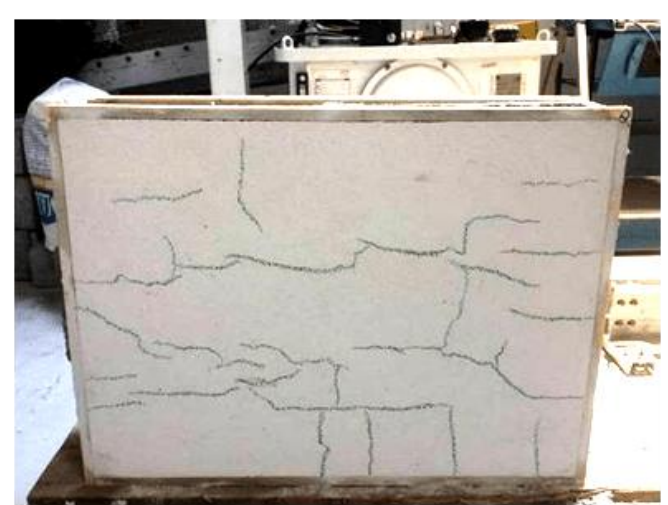

(b) Reforço tela 1- Galvanizada quadrada

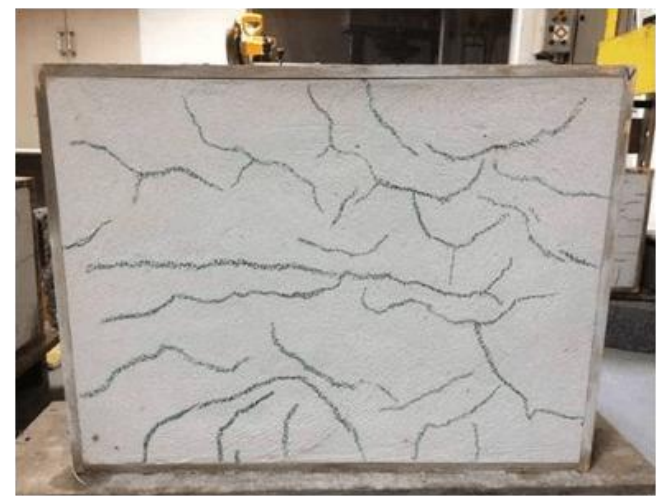

(d) Reforço tela 3-Galvanizada hexagonal

482 Musse, D. S.; Coelho, V. A.; Gonçalves, J. P.; Silva, F. G. S. 
Quadro 3 - Termogramas dos revestimentos submetidos ao carregamento térmico de $80{ }^{\circ} \mathrm{C}$

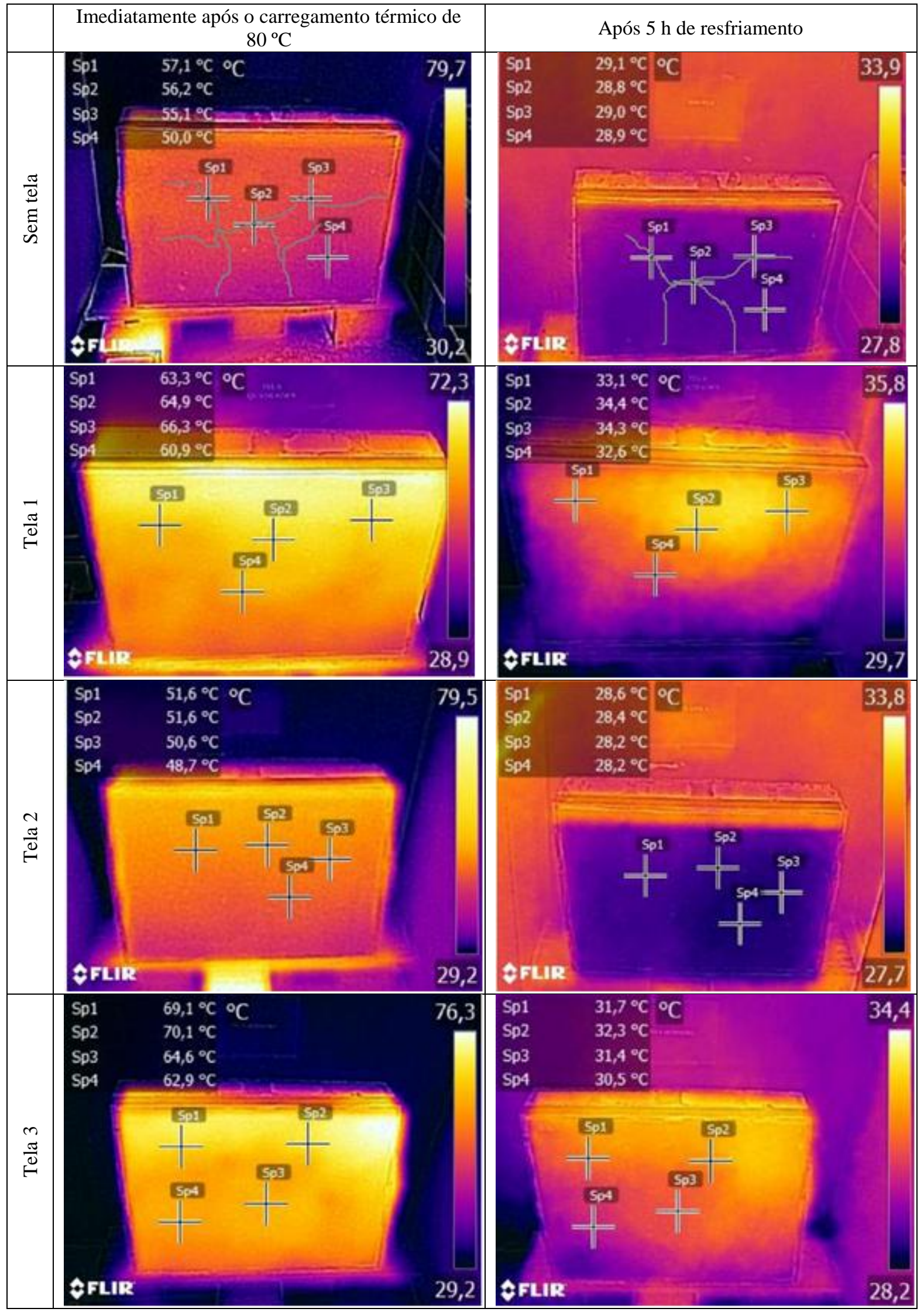


Tabela 5 - Evolução do DeltaT nos primeiros momentos do resfriamento dos painéis submetidos ao carregamento térmico de $80^{\circ} \mathrm{C}$

\begin{tabular}{|c|c|c|c|c|c|c|c|c|c|c|c|c|}
\hline \multirow{3}{*}{ Leitura } & \multicolumn{12}{|c|}{ DeltaT $\left({ }^{\circ} \mathrm{C}\right)$} \\
\hline & \multicolumn{3}{|c|}{ Sem tela } & \multicolumn{3}{|c|}{ Tela 1} & \multicolumn{3}{|c|}{ Tela 2} & \multicolumn{3}{|c|}{ Tela 3} \\
\hline & sp1 & sp2 & sp3 & sp1 & sp2 & sp3 & sp1 & sp2 & sp3 & sp1 & sp2 & sp3 \\
\hline Inicial & 7,1 & 6,2 & 5,1 & 2,4 & 4,0 & 5,4 & 2,9 & 2,9 & 1,9 & 6,2 & 7,2 & 1,7 \\
\hline $30 \mathrm{~min}$ & 5,2 & 3,7 & 3,4 & 4,2 & 3,9 & 6,7 & 2,4 & 3,0 & 1,8 & 7,0 & 4,5 & 1,2 \\
\hline $60 \mathrm{~min}$ & 4,4 & 3,0 & 1,9 & 2,6 & 4,1 & 4,8 & 1,2 & 1,8 & 1,2 & 5,4 & 3,3 & 0,9 \\
\hline
\end{tabular}

Figura 13 - Estudo da fissuração dos revestimentos com espessura de $5 \mathrm{~cm}$

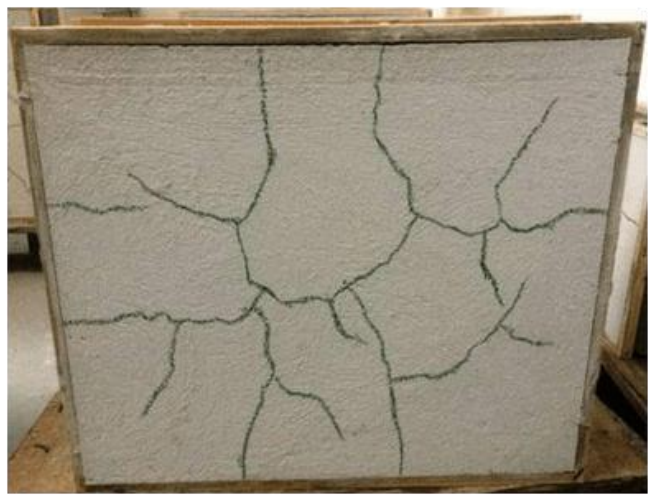

(a) Sem tela

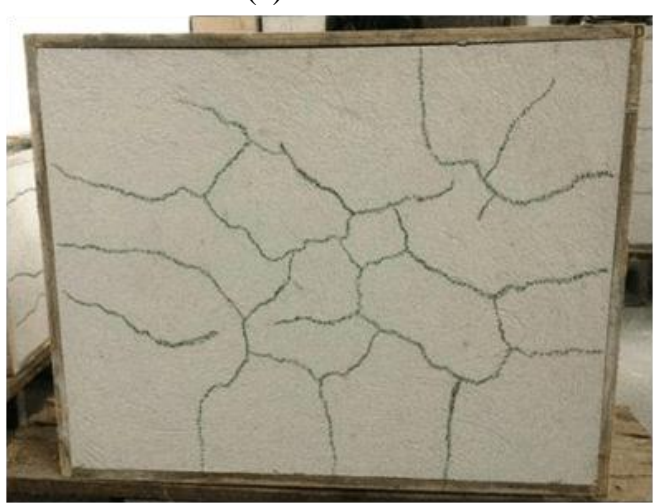

(c) Reforço tela 2- Tela de polietileno

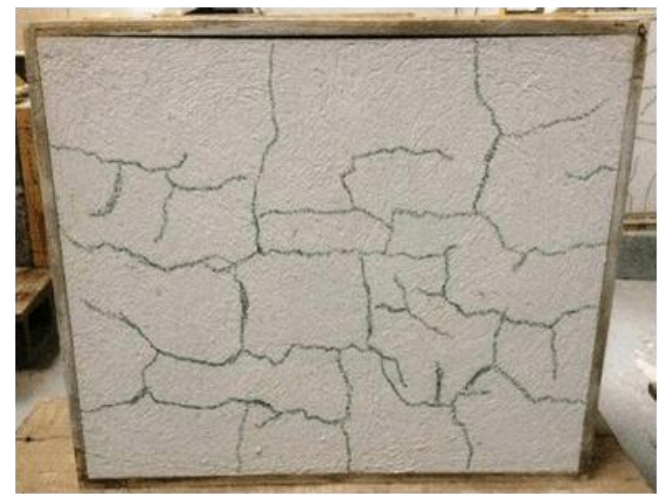

(b) Reforço tela 1- Galvanizada quadrada

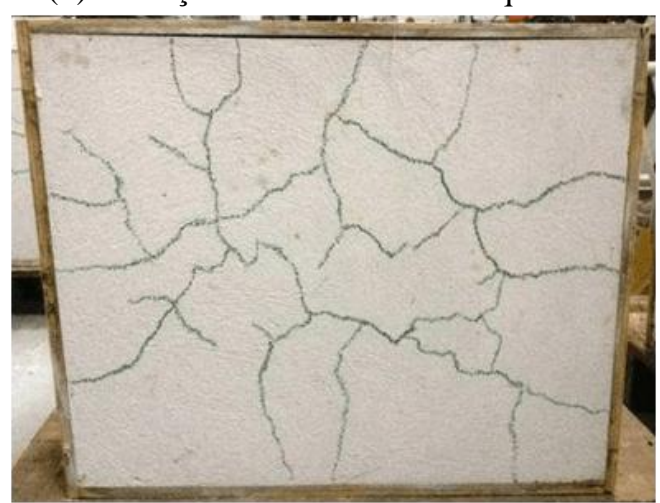

(d) Reforço tela 3- Galvanizada hexagonal

\section{Mapeamento e índice de fissuração dos painéis}

A fissuração induzida pelo carregamento térmico de $80{ }^{\circ} \mathrm{C}$ aplicado nos revestimentos com espessura de 5 $\mathrm{cm}$ reforçados com as três diferentes telas nos painéis podem ser observados na Figura 13.

A incidência de fissuração dos painéis estudados reflete um acréscimo desse índice em relação ao painel sem reforço de $64,04 \%$ para o reforço realizado com a tela 1 , de $27,61 \%$ para o revestimento reforçado com a tela 2 e de $39,81 \%$ para o painel reforçado com atela 3.

Nessa espessura, a função do reforço das argamassas ficou mais evidente, uma vez que os esforços solicitados foram redistribuídos por toda a extensão dos revestimentos, promovendo maior incidência de fissuras com menores aberturas. Constata-se que a tela 1 e a tela 3 mostraram melhor funcionamento na absorção das tensões, concedendo maior elasticidade ao revestimento para que ele tivesse a capacidade de suportar os esforços de tração promovidos pelo carregamento térmico nas duas diferentes espessuras do reboco.

A redução das aberturas está associada, segundo os estudos de Speck (2014), aos valores de dilatação térmica linear das telas de aço, uma vez que apresentam menores valores e mostraram atuação em várias

484 Musse, D. S.; Coelho, V. A.; Gonçalves, J. P.; Silva, F. G. S. 
direções dos revestimentos, reduzindo as movimentações de origem térmica ocorridas no sistema e, consequentemente, no aparecimento de fissuras.

\section{Avaliação da eficiência do tipo de reparo das fissuras}

A recuperação realizada nos revestimentos para os dois métodos aplicados foi considerada eficiente, devido ao não aparecimento de fissuras até 14 dias desua realização e após o carregamento térmico de $38^{\circ} \mathrm{C}$ e de $80^{\circ} \mathrm{C}$. Isso comprova que as fissuras ocorridas nos revestimentos não sofreram modificações no decorrer do tempo, sendo, portanto, passivas. As imagens termográficas mostraram comportamento similar nos dois carregamentos e em todos os tipos de reforço, não tendo sido encontrados vestígios de fissuras.

Os termogramas realizados nos painéis logo após a retirada do carregamento térmico são apresentados no Quadro 4.

As temperaturas nos pontos (sp1) correspondentes ao sistema de recuperação com massa acrílica e tela de poliéster apresentaram menores temperaturas, comparadas aos locais onde o revestimento permaneceu íntegro, sem fissuras e sem tratamento (sp3). As maiores temperaturas adquiridas nos painéis foram nos locais com tratamento com resina epóxi (sp2).

Esse aumento de temperatura na região do tratamento com epóxi está relacionado com a absorção da radiação da região mais escura, uma vez que as emissões de energia em zonas de menor reflexão geram aumento na taxa de energia absorvida nessas zonas. Sendo assim, os materiais utilizados para os revestimentos dos painéis são considerados opacos. Quando a taxa de reflexão é mínima, a taxa de absorção tende a ser maior quando a cor se torna mais escura.

\section{Avaliação do comportamento dos revestimentos reforçados quando submetidos ao impacto}

Os impactos, que correspondem aos choques da esfera por energia de impacto, não provocaram destacamentos e ruínas nos revestimentos com espessura de $2,5 \mathrm{~cm}$. As profundidades das mossas são apresentadas na Figura 14.

Como a esfera é lançada aleatoriamente, a profundidade das mossas varia. Realizando a análise de variância estatística (ANOVA), observa-se na Tabela 6 que os valores encontrados nas profundidades não apresentaram modificações significativas quando comparados com os do revestimento sem reforço.

Para os impactos realizados com energia potencial de $10 \mathrm{~J}$, as profundidades das mossas foram menores que 2,0 $\mathrm{mm}$. Aumentando a energia para $20 \mathrm{~J}$, esses valores variaram de 2,6 $\mathrm{mm}$ a 3,0 $\mathrm{mm}$. Isso, segundo a NBR 15575-2 (ABNT, 2013a),indicaque os revestimentos se enquadram no nível mínimo de desempenho, considerando qualquer profundidade de mossas, não ocorrência de ruínas e admitidas falhas superficiais como mossas, fissuras e desagregações.

A análise dos revestimentos dos painéis destacou maiores comprimentos e fissuras com aberturas de $0,3 \mathrm{~mm}$ nos revestimentos sem reforço. $\mathrm{O}$ revestimento reforçado com a tela 1 obteve microfissuras (menores que $0,05 \mathrm{~mm}$ de abertura), e os reforçados com as telas 2 e 3 , aberturas das fissuras de $0,1 \mathrm{~mm}$.

O resultado do ensaio condiz com os valores encontrados no ensaio de resistência à tração na flexão das argamassas reforçadas e ratifica que o reforço de produtos cimentícios com fibras melhora a resistência ao impacto e contribui para a resistência à flexão do sistema, sendo ainda um fator que fortalece a ligação entre substrato e argamassa (TOIHIDUL ISLAM; BINDIGANAVILE, 2011), e, conforme observado por Wang et al. (2016), reduz a formação de pequenas fissuras, sinal de melhoria da integridade do material. 
Quadro 4 - Termogramas após a aplicação do carregamento térmico

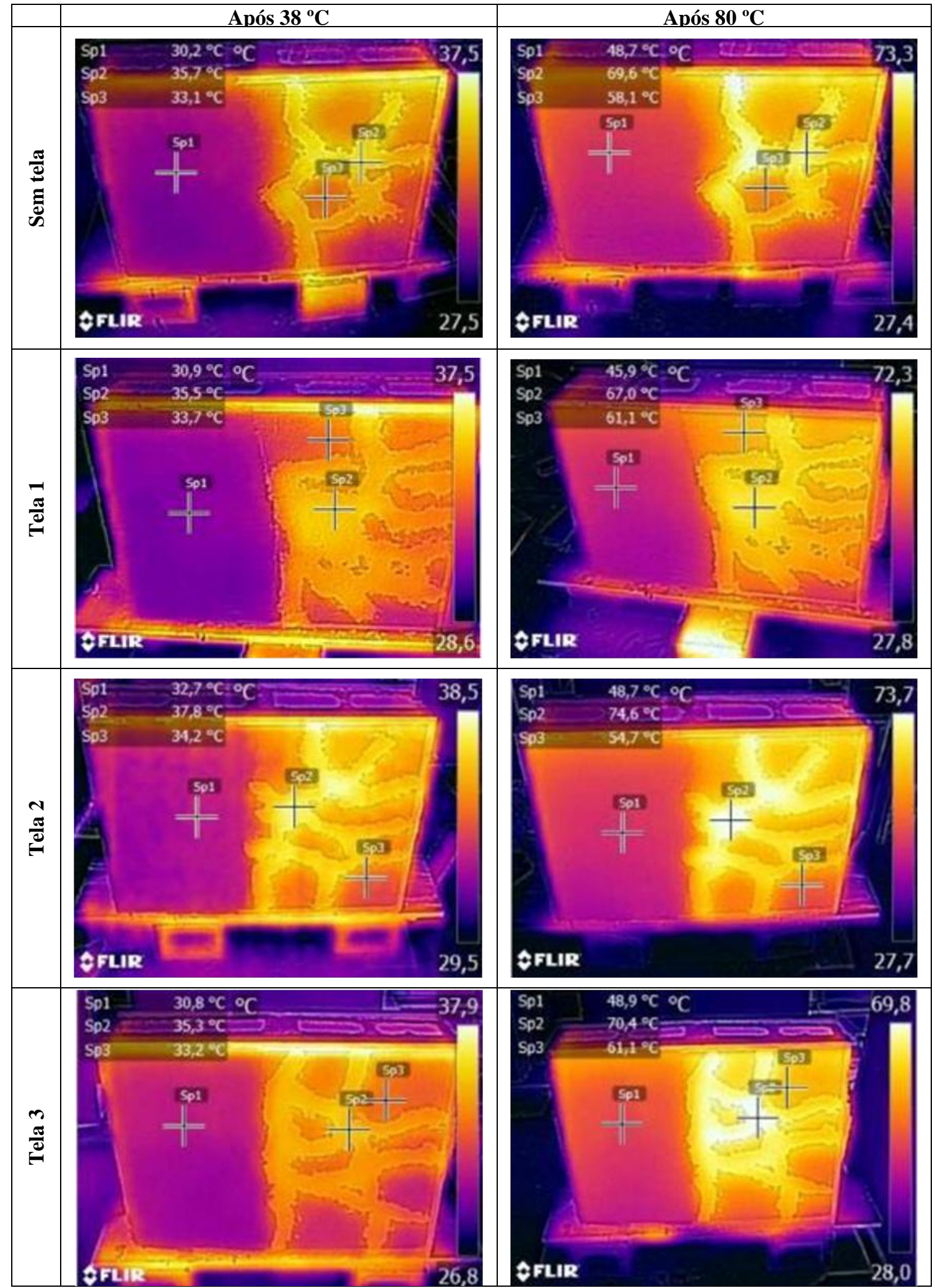

486 Musse, D. S.; Coelho, V. A.; Gonçalves, J. P.; Silva, F. G. S. 
Figura 14 - Resultados dos ensaios de corpo rígido dos painéis

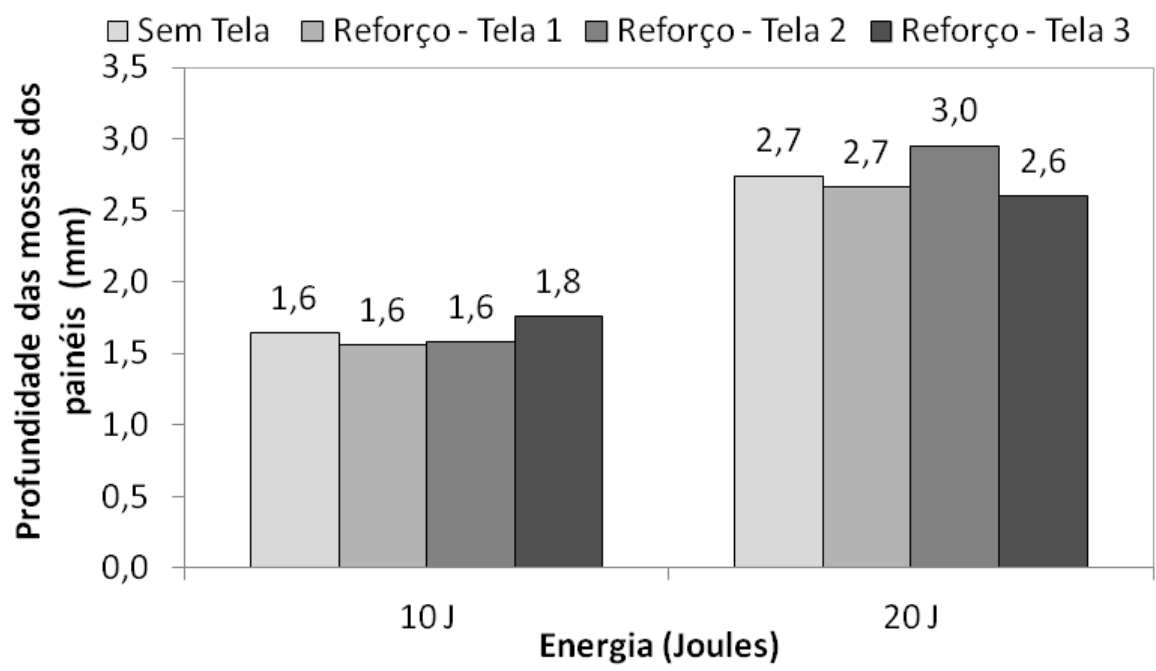

Tabela 6 - Análise das profundidades das mossas em relação ao painel de referência

\begin{tabular}{c|c|c|c|c|c}
\hline $\begin{array}{c}\text { Energia de } \\
\text { impacto (J) }\end{array}$ & Revestimentos dos painéis & F & Valor-p & F-crítico & Significativo \\
\hline \multirow{3}{*}{10} & Semtela x Reforçotela 1 & 0,87 & 0,3629 & & Não \\
& Semtela x Reforçotela 2 & 0,56 & 0,4644 & 4,41 & Não \\
& Semtela x Reforçotela 3 & 1,17 & 0,2937 & & Não \\
\hline \multirow{2}{*}{20} & Semtela x Reforçotela 1 & 0,22 & 0,6428 & & Não \\
& Semtela x Reforçotela 2 & 1,07 & 0,3146 & 4,41 & Não \\
& Semtela x Reforçotela 3 & 0,47 & 0,5000 & & Não \\
\hline
\end{tabular}

\section{Conclusões}

Foi avaliada a influência do uso de telas em revestimentos argamassados quanto acaracterísticas mecânicas e desempenho após a exposição térmica, sendo também observados os efeitos de dois tipos de reparos de fissuração, do que se pode concluir que:

(a) a presença das telas nos painéis reduziu significativamente o tamanho das fissuras, de modo que, para o carregamento térmico aplicado, sua presença só foi visível nos termogramas para os revestimentos sem reforço;

(b) as telas galvanizadas de malha quadrada e hexagonal de viveiro mostraram eficiência no controle das aberturas das fissuras ao absorver as tensões ocasionadas no sistema e fornecer resistência para suportar as tensões de tração promovidas pelo carregamento térmico nas duas diferentes espessuras do reboco, enquanto o reforço realizado com a malha hexagonal de polietileno apresentou o mesmo desempenho dos revestimentos sem tela;

(c) a tela eletrossoldada galvanizada foi a que promoveu as melhores condições para absorver a energia de impacto e produzir menores fissuras, e todos os revestimentos se enquadram no nível mínimo de desempenho segundo a NBR 15575-2 (ABNT, 2013b), restringindo-se à avaliação da resistência superficial do elemento;

(d) os resultados mecânicos apontam para aredução da resistência à compressão, à tração por compressão diametral e ao cisalhamento das argamassas quando se utilizam as telas;no entanto, tais propriedades podem ser sensivelmente afetadas pelo posicionamento delas nos corpos de prova;

(e) a inserção das telas na zona tracionada dos corpos de prova proporcionou os melhores desempenhos nas argamassas, principalmente para a tela eletrossoldada galvanizada; e 
(f) os reforços realizados com massa acrílica e tela de poliéster, juntamente com os reforços com resina epóxi, apresentaram desempenho adequado, pois não apresentaram fissuras com aplicação do carregamento térmico de $38^{\circ} \mathrm{C}$ e de $80^{\circ} \mathrm{C}$.

Dessa forma, os resultados apontam para a tela eletrossoldada galvanizada de malha quadrada como a melhor opção para reforço de revestimentos de fachada devido aos resultados obtidos nos ensaios de resistência à flexão e no controle de fissuração dos revestimentos.

No geral, não há dificuldades de aplicação das telas estudadas para reforço de revestimentos, e a escolha entre os diferentes tipos é usualmente feita mediante a cotação de preço por metro quadrado. Durante o período de execução desta pesquisa, a tela quadrada eletrossoldada possuía o valor mais elevado por metro quadrado, de $\mathrm{R} \$ 13,91$, enquanto a tela de polietileno de malha hexagonal custava $\mathrm{R} \$ 4,58$, e a tela galvanizada de malha hexagonal, $\mathrm{R} \$ 10,03$.

Dado o exposto, os resultados desta pesquisa comprovam a eficiência da tela galvanizada eletrossoldada em reforçar os revestimentos argamassados devido à capacidade de distribuir as tensões e dispor de boa aderência com a matriz cimentícia. No entanto, devido aos reduzidos estudos nessa área, torna-se necessário o desenvolvimento de trabalhos com maior aprofundamento para compreensão da influência da dimensão dos fios, do tamanho das malhas e do tipo de material para aplicação de telas em reforços, principalmente sob condições de variação térmica.

\section{Referências}

ALTOÉ, L.; OLIVEIRA FILHO, D. Termografia infravermelha aplicada à inspeção de edifícios. Tecnológica, v.7, p.55-59, 2012.

AMERICAN SOCIETY FOR TESTING AND MATERIALS. E1933-99: standard test methods for measuring and compensating for emissivity using infrared imaging radiometers. West Conshohocken, 1999.

ANTUNES, G. R.; MASUERO, A. B. Proposição de ensaio de resistência à tração de tela metálica adotada no reforço de argamassa. In: SIMPÓSIO BRASILEIRO DE TECNOLOGIA DAS ARGAMASSAS, 10., Fortaleza, 2013. Anais [...] Fortaleza, 2013.

ANTUNES, G. R.; MASUERO, A. B.; MAÇANEIRO, M. N. Avaliação do desempenhode argamassa reforçada com tela metálica através do ensaio de tração na flexão. In: ENCONTRO NACIONAL DE TECNOLOGIA DO AMBIENTE CONSTRUÍDO, 15., Maceió, 2014. Anais [...] Maceió, 2014.

ANTUNES, G. R.; MASUERO, A. B. Flexural tensile strength in mortar coating reinforced with different types of metal mesh: A statistical comparison. Construction and Building Materials, v. 121, p. 559-568, 2016.

ASSOCIAÇÃO BRASILEIRA DE NORMAS TÉCNICAS. NBR 13276: argamassa para assentamento e revestimento de paredes e tetos: preparo da mistura e determinação do índice de consistência. Rio de Janeiro, 2005 c.

ASSOCIAÇÃO BRASILEIRA DE NORMAS TÉCNICAS. NBR 13277: argamassa para assentamento de paredes e revestimento de paredes e tetos: Determinação da retenção de água. Rio de Janeiro, 2005d.

ASSOCIAÇÃO BRASILEIRA DE NORMAS TÉCNICAS. NBR 13278: argamassa para assentamento e revestimento de paredes e tetos: determinação da densidade de massa e do teor de ar incorporado. Rio de Janeiro, 2005e.

ASSOCIAÇÃO BRASILEIRA DE NORMAS TÉCNICAS. NBR 13279: argamassa para assentamento e revestimento de paredes e tetos: determinação da resistência à tração na flexão e à compressão. Rio de Janeiro, 2005f.

ASSOCIAÇÃO BRASILEIRA DE NORMAS TÉCNICAS. NBR 13280: argamassa para assentamento e revestimento de paredes e tetos: determinação da densidade de massa aparente no estado endurecido. Rio de Janeiro, $2005 \mathrm{~g}$.

ASSOCIAÇÃO BRASILEIRA DE NORMAS TÉCNICAS. NBR 13281: argamassa para assentamento e revestimento de paredes e tetos: requisitos. Rio de Janeiro, 2005a.

ASSOCIAÇÃO BRASILEIRA DE NORMAS TÉCNICAS. NBR 13749: argamassa para assentamento de paredes e revestimento de paredes e tetos: especificação. Rio de Janeiro. 2013a.

488 Musse, D. S.; Coelho, V. A.; Gonçalves, J. P.; Silva, F. G. S. 
ASSOCIAÇÃO BRASILEIRA DE NORMAS TÉCNICAS. NBR 15258: argamassa para assentamento e revestimento de paredes e tetos: determinação da resistência potencial de aderência à tração. Rio de Janeiro, $2005 b$.

ASSOCIAÇÃO BRASILEIRA DE NORMAS TÉCNICAS. NBR 15259: argamassa para assentamento e revestimento de paredes e tetos: determinação da absorção de água por capilaridade e do coeficiente de capilaridade. Rio de Janeiro, 2005h.

ASSOCIAÇÃO BRASILEIRA DE NORMAS TÉCNICAS. NBR 15270-3: componentes cerâmicos: parte 3: blocos cerâmicos para alvenaria estrutural e de vedação: métodos de ensaio. Rio de Janeiro, 2005 i.

ASSOCIAÇÃO BRASILEIRA DE NORMAS TÉCNICAS. NBR 15575-2: edificações habitacionais: desempenho: parte 2: requisitos para os sistemas estruturais. Rio de Janeiro, 2013b.

ASSOCIAÇÃO BRASILEIRA DE NORMAS TÉCNICAS. NBR 15575-4: edificações habitacionais: desempenho: parte 4: requisitos para os sistemas de vedações verticais internas e externas. Rio de Janeiro, 2013a.

ASSOCIAÇÃO BRASILEIRA DE NORMAS TÉCNICAS. NBR 5739: concreto: ensaios de compressão de corpos-de-prova cilíndricos. Rio de Janeiro, 2007.

ASSOCIAÇÃO BRASILEIRA DE NORMAS TÉCNICAS. NBR 6136: bloco vazado de concreto simples para alvenaria estrutural. Rio de Janeiro, 2014.

ASSOCIAÇÃO BRASILEIRA DE NORMAS TÉCNICAS. NBR 7200: execução de revestimento de paredes e tetos de argamassas inorgânicas: procedimento. Rio de Janeiro, 1998.

ASSOCIAÇÃO BRASILEIRA DE NORMAS TÉCNICAS. NBR 7215: cimento Portland: determinação da resistência à compressão. Rio de Janeiro, 1997.

ASSOCIAÇÃO BRASILEIRA DE NORMAS TÉCNICAS. NBR 7222: argamassa e concreto-determinação da resistência à tração por compressão diametral de corposdeprova cilíndricos. Rio de Janeiro, 2011.

AZEVEDO, A. et al. Compression behaviour of clay bricks prisms, wallets and walls: coating influence.

Revista de la Construcción, v. 18, n. 1, p. 123-133, 2019.

BARBOSA, C. S.; LOURENÇO, P. B.; HANAI, J. B. On the compressive strength prediction for concrete masonry prisms. Materials and Structures/Materiaux et Constructions, v. 43, n. 3, p. 331-344, 2010.

BAUER, E. et al. Analysis of building facade defects using infrared thermography: laboratory studies. Journal of Building Engineering, v. 6, p. 93-104, 2016.

BAUER, E.; PAVÓN. E. Termografia de infravermelho na identificação e avaliação de manifestações patológicas em edifícios. Concreto \& Construções, v. 79, p. 93-98, 2015.

EWING, B.D.; KOWALSKY, M. J. Compressive Behavior of Unconfined and Confined Clay Brick Masonry Compressive Behavior of Unconfined and Confined Clay. Journal of Structural Engineering, v.130, n. 4, p. 650-661, 2004.

FAUZAN, F. A. I. et al. Experimental study on masonry building strengthened with ferrocement layers. International Journal of GEOMATE, v. 14, n. 45, p. 84-90, 2018.

FIORITO, A. J. S. I. Manual de argamassa e revestimento: estudo e procedimento de execução. São Paulo: Pini, 1994.

GOMES, A. O.; NEVES, C.; SOUZA, S. L. M. Utilização de telas em sistemas de revestimentos com argamassa. In: SIMPÓSIO BRASILEIRO DE TECNOLOGIA DE ARGAMASSAS, 7., Recife, 2007. Anais [...] Recife, 2007.

KOUTAS, L. N. et al.Strengthening of concrete structures with textile reinforced mortars: state-of-the-art review. JournalofComposites for Construction, v. 23, n. 1, p. 3118001, 2018.

MENDONÇA, L. V. Termografia Por Infravermelhos: inspecção de betão. Engenharia e Vida, v. 1, n. 16, p. 53-57, 2005.

MOHAMAD, G.; LOURENÇO, P. B.; ROMAN, H. R. Mechanics of hollow concrete block masonry prisms under compression: Review and prospects. Cement and Concrete Composites, v. 29, n. 3, p. 181-192, 2007. 
MUGHAL, U. A.; SALEEM, M. A.; ABBAS, S. Comparative study of ferrocement panels reinforced with galvanized iron and polypropylene meshes. Construction and Building Materials, v. 210, p. 40-47, 2019.

OLIVEIRA, R. A. et al. Edificações em alvenaria resistente na região metropolitana do Recife. Ambiente Construído, Porto Alegre, v. 17, n. 2, p. 175-199, abr./jun. 2017.

OLIVEIRA, R. A. et al. Structural performance of unreinforced masonry elements made with concrete and horizontally perforated ceramic blocks: laboratory tests. Construction and Building Materials, v. 182, p. 20-34, 2018.

PADALU, P. K. V. R.; SINGH, Y.; DAS, S. Tensile properties of wire and fibre reinforced cementitious matrix composites for strengthening of masonry. Structures, v. 23, p. 164-179, 2020.

PINTO, K. W. et al. Método de ensaio de resistência ao cisalhamento em materiais cimentícios. In: CONGRESSO BRASILEIRO DO CONCRETO, 58., Belo Horizonte, 2016. Anais [...] São Paulo: IBRACON, 2016.

POZZOBON, M. A. et al. Verificação das características de telas metálicas utilizadas para reforçar revestimentos argamassados frente a esforços de tração. In: CONGRESSO REGIONAL DE INICIAÇÃO CIENTÍFICA E TECNOLÓGICA EM ENGENHARIA, 26., Alegrete, 2014. Anais [...] Alegrete, 2014.

SCHIMELFENIG, B. et al. Análise da influência de telas utilizadas como reforço em revestimento de argamassa de fachada frente a esforços de tração. Revista Matéria, v. 23, n. 3, 2018.

SHERMI, C.; DUBEY, R. N. In-plane behaviour of unreinforced masonry panel strengthened with welded wire mesh and mortar. Construction and Building Materials, v. 178, p. 195-203, 2018.

SILVA, F. G. S.; BAUER, E. Avaliação da fissuração em argamassas. In: SIMPÓSIO BRASILEIRO DE TECNOLOGIA DE ARGAMASSAS, 8., Curitiba, 2009. Anais [...] Curitiba, 2009.

SPECK, J. A. Análise do desempenho de placas cimentícias através da adição de fibras e telas, visando a redução de deformações térmicas e patologias. 2014. 112 f. Dissertação (Mestrado em Engenharia Civil) -Escola de Engenharia, Universidade Federal do Rio Grande do Sul, Porto Alegre, 2014.

TOIHIDUL ISLAM, M.; BINDIGANAVILE, V. The impact resistance of masonry units bound with fibre reinforced mortars. Construction and Building Materials, v. 25, n. 6, p. 2851-2859, 2011.

WANG, S. et al. Resistance of high-performance fiber-reinforced cement composites against high-velocity projectile impact. International Journal of Impact Engineering, v. 95, p. 89-104, 2016.

\section{Agradecimentos}

Os autores agradecem ao Programa de Pós-Graduação em Engenharia Civil (PPEC/UFBA), à Coordenação de Aperfeiçoamento de Pessoal de Nível Superior (CAPES) e à Fundação de Amparo à Pesquisa do Estado da Bahia (FAPESB) pelo suporte, apoio financeiro e incentivo à pesquisa. 


\section{Daniela Santana Musse}

Mestrado em Engenharia Ambiental Urbana, Escola Politécnica | Universidade Federal da Bahia | Rua Prof. Aristídes Novis, 2 | Salvador BA - Brasil | CEP 402010-630 | Tel.: (71) 98883-6971 |E-mail: danielamusse@yahoo.com.br

\section{Vinícius Almeida Coelho}

Programa de Pós-Graduação em Engenharia Civil, Escola Politécnica | Universidade Federal da Bahia | Tel.: (71) 98638-7034 | E-mail: mrvoelho@gmail.com

\section{Jardel Pereira Gonçalves}

Departamento de Construção e Estruturas, Escola Politécnica | Universidade Federal da Bahia | Tel.: (71) 3283-9485 | E-mail: jardelpg@ufba.br

\section{Francisco Gabriel Santos Silva}

Departamento de Construção e Estruturas, Escola Politécnica | Universidade Federal da Bahia | Tel.: (71) 3283-9526 | E-mail: fgabriel.ufba@gmail.com

\section{Ambiente Construído}

Revista da Associação Nacional de Tecnologia do Ambiente Construído

Av. Osvaldo Aranha, $99-3^{\circ}$ andar, Centro

Porto Alegre - RS - Brasil

CEP $90035-190$

Telefone: +55 (51) 3308-4084

Fax: +55 (51) 3308-4054

www.seer.ufrgs.br/ambienteconstruido

E-mail: ambienteconstruido@ufrgs.br

(c) (i) This is an open-access article distributed under the terms of the Creative Commons Attribution License. 